\title{
Article \\ Nucleotide-Binding Leucine-Rich Repeat Genes CsRSF1 and CsRSF2 Are Positive Modulators in the Cucumis sativus Defense Response to Sphaerotheca fuliginea
}

\author{
Xue Wang ${ }^{1}$, Qiumin Chen ${ }^{1,2}$, Jingnan Huang ${ }^{1}$, Xiangnan Meng ${ }^{1}$, Na Cui ${ }^{1}$, Yang Yu ${ }^{1, *}$ and Haiyan Fan ${ }^{1,3, *}$ \\ 1 College of Bioscience and Biotechnology, Shenyang Agricultural University, Shenyang 110866, China; \\ wxue9507@163.com (X.W.); qiuminchen2019@163.com (Q.C.); 15037943009@163.com (J.H.); \\ 2019500018@syau.edu.cn (X.M.); cuina@syau.edu.cn (N.C.) \\ 2 College of Horticulture, Shenyang Agricultural University, Shenyang 110866, China \\ 3 Key Laboratory of Protected Horticulture of Ministry of Education, Shenyang Agricultural University, \\ Shenyang 110866, China \\ * Correspondence: yy7603@163.com (Y.Y.); hyfan74@syau.edu.cn (H.F.)
}

check for updates

Citation: Wang, X.; Chen, Q.; Huang, J.; Meng, X.; Cui, N.; Yu, Y.; Fan, H. Nucleotide-Binding Leucine-Rich Repeat Genes CsRSF1 and CsRSF2 Are Positive Modulators in the Cucumis sativus Defense Response to Sphaerotheca fuliginea. Int. J. Mol. Sci. 2021, 22, 3986. https://doi.org/ $10.3390 /$ ijms 22083986

Academic Editor: Bartolome Sabater

Received: 17 March 2021

Accepted: 8 April 2021

Published: 13 April 2021

Publisher's Note: MDPI stays neutral with regard to jurisdictional claims in published maps and institutional affiliations.

Copyright: (c) 2021 by the authors. Licensee MDPI, Basel, Switzerland. This article is an open access article distributed under the terms and conditions of the Creative Commons Attribution (CC BY) license (https:/ / creativecommons.org/licenses/by/ $4.0 /)$.

\begin{abstract}
Cucumber powdery mildew caused by Sphaerotheca fuliginea is a leaf disease that seriously affects cucumber's yield and quality. This study aimed to report two nucleotide-binding site-leucinerich repeats (NBS-LRR) genes CSRSF1 and CSRSF2, which participated in regulating the resistance of cucumber to $S$. fuliginea. The subcellular localization showed that the CsRSF1 protein was localized in the nucleus, cytoplasm, and cell membrane, while the CsRSF2 protein was localized in the cell membrane and cytoplasm. In addition, the transcript levels of CsRSF1 and CsRSF2 were different between resistant and susceptible cultivars after treatment with exogenous substances, such as abscisic acid (ABA), methyl jasmonate (MeJA), salicylic acid (SA), ethephon (ETH), gibberellin (GA) and hydrogen peroxide $\left(\mathrm{H}_{2} \mathrm{O}_{2}\right)$. The expression analysis showed that the transcript levels of CsRSF1 and CsRSF2 were correlated with plant defense response against $S$. fuliginea. Moreover, the silencing of CsRSF1 and CsRSF2 impaired host resistance to S. fuliginea, but CsRSF1 and CsRSF2 overexpression improved resistance to $S$. fuliginea in cucumber. These results showed that CsRSF1 and CsRSF2 genes positively contributed to the resistance of cucumber to $S$. fuliginea. At the same time, CsRSF1 and CSRSF2 genes could also regulate the expression of defense-related genes. The findings of this study might help enhance the resistance of cucumber to $S$. fuliginea.
\end{abstract}

Keywords: Cucumis sativus; NBS-LRR; expression analysis; Sphaerotheca fuliginea; transient genetic transformation

\section{Introduction}

Cucumber (Cucumis sativus) is one of the largest protected vegetable cultivation in China. Cucumber powdery mildew caused by $S$. fuliginea is an important disease of cucumber that seriously affects cucumber's yield and quality. Cucumber powdery mildew has some characteristics, such as wide distribution, short incubation period and so on [1]. It reduces cucumber yield by $20 \%-50 \%$, or even $0 \%$ [2]. At present, planting resistant cultivars is the most important and effective way of controlling cucumber powdery mildew. It is vital to clone key genes related to the infection of $S$. fuliginea and explore its mechanism of action so as to improve the resistance of cucumber to $S$. fuliginea.

Producing toxins to destroy the host's defense system and make plants susceptible to diseases is one way in which pathogens infect plants [3]. To control pathogens, plants have formed an innate immune system $[4,5]$. This immune system has two layers: the first layer is called pathogen-associated molecular patterns (PAMPs)-triggered immunity (PTI), which is the recognition of PAMPs by pattern-recognition receptors on the cell surface; the second layer is called effector-triggered immunity (ETI), which is the recognition of pathogenic factors within the bacteria. This process mainly triggers a hypersensitive response (HR), 
which causes programmed cell death to block pathogens from absorbing nutrients and limit the proliferation and spread of hyphae [6]. Furthermore, HR can activate ethylene (ET), SA, jasmonic acid (JA), and other defense signaling pathways [7,8]. Plant disease resistance proteins (R proteins) are vital in the ETI [9]. Nucleotide-binding site-leucine-rich repeat (NBS-LRR) proteins are the main types of $R$ proteins.

NBS-LRR proteins are classified into two subfamilies based on the motifs located in the N-terminal region [10]: TIR-NBS-LRR (TNL) and non-TIR-NBS-LRR (CC-NBS-LRR $(\mathrm{CNL})$ ) [11]. These proteins have three domains: nucleotide-binding site (NBS) (nucleotidebinding and ATPase (NB-ARC)) domain, leucine-rich repeats (LRR) domain, and Tollinterleukin receptor (TIR)/coiled-coil (CC) domain. The NBS domain can change ADP to ATP so that it can stimulate downstream HR [12]. It can also participate in all kinds of processes, such as cell growth, differentiation, cytoskeletal organization, vesicle transport, and defense. The LRR domain is important in the protein-protein interaction [13]. The TIR domain is involved in resistance specificity and signaling [14]. The CC domain is the key to induce an immune response by interacting with downstream signal components [15].

The NBS-LRR protein senses pathogen effectors and causes them to trigger an immune response of plants to develop a defense response against pathogens, such as bacteria, viruses, and fungi [16]. Genes encoding the NBS-LRR protein in different plants can confer resistance to plants directly or indirectly, thus helping plants resist attack by pathogens $[17,18]$. For example, the NBS-LRR gene Pm60 confers resistance to powdery mildew in wheat [19]; the NBS-LRR gene SacMi participates in plant resistance to Meloidogyne spp. in wild eggplant [20]; and the tomato NBS-LRR gene expression has a positive correlation with plant resistance to Phytophthora infestans [21].

A complex network of different signal transductions exists in the interaction between plants and pathogens [22]. The NBS-LRR protein can directly or indirectly recognize and interact with avirulence (Avr) protein products [23]. This recognition of effectors can change the NBS-LRR protein from an inhibited state to an activated state, thereby activating downstream signal transduction to generate a defense response. The barley CNL protein MLA10 can interact with WRKY (transcription repressor) and MYB6 (transcription activator) to activate the defense response [24,25]. The rice CNL protein $\mathrm{Pb} 1$ interacts with OsWRKY45 and stabilizes it to develop resistance to Magnaporthe oryzae [26]. The Arabidopsis TNL protein RPS4 can recognize AvrRps4 to activate HR [27-29]. The potato CNL protein Rx recognizes the potato virus coat protein (PVX CP) and interacts with the cytoplasmic activation protein RanGAP2 to activate the signaling pathway [30].

The NBS-LRR function in S. fuliginea infection and the defense mechanisms have not been described in cucumber. Wan et al. performed a genome-wide analysis of NBSencoding genes within the whole cucumber genome. Moreover, they found two proteins, Cucsa.102240 and Cucsa.123410, which were predicted to have a domain with a sequence similar to the resistance to powdery mildew 8 (RPW8) Arabidopsis powdery mildew resistance gene family [31,32]. In addition, we used bioinformatics software to analyze these two proteins and found they have RPW8 domains. Therefore, they may be involved in the interaction between cucumber and S. fuliginea or may contribute to defense responses against S. fuliginea. They were named CsRSF1 and CsRSF2. This study aimed to report whether two NBS-LRR genes CsRSF1 and CsRSF2, participated in regulating the resistance of cucumber to S. fuliginea. In this study, CsRSF1 (Cucsa.102240) and CsRSF2 (Cucsa.123410) were cloned from B21-a-2-2-2 (highly susceptible to S. fuliginea) and B21-a-2-1-2 (highly resistant to $S$. fuliginea); their sequences showed no differences between the resistant and susceptible cultivars. They were typical NBS-LRR proteins as detected by the bioinformatics analysis. CSRSF1 and CSRSF2 were induced upon S. fuliginea infection, but their expression patterns were different. Subcellular localization analysis showed that CsRSF1 and CsRSF2 proteins were located in the plasma membrane and cytoplasm, whereas the CsRSF1 protein was also located in the nucleus. These genes responded differently to exogenous substances. The defense role dissections of CsRSF1/CsRSF2-silencing and 
CsRSF1/CsRSF2-overexpressing cucumber plants indicated that CsRSF1/CsRSF2, acting as positive regulators, were required for host resistance response to $S$. fuliginea.

\section{Results}

\subsection{Gene Cloning and Sequence Analysis of CsRSF1 and CsRSF2}

According to the sequence of the target gene found in the Phytozome database (https: / / phytozome.jgi.doe.gov/pz/portal.html, last accessed on 9 April 2021), the fulllength CDS sequences of CsRSF1/CsRSF2 were cloned from the experimental materials of B21-a-2-1-2 and B21-a-2-2-2. The comparison of the sequences showed no difference in CDS sequences of CsRSF1/CsRSF2 between the B21-a-2-1-2 variety and B21-a-2-2-2 variety. The full CDS sequence of CSRSF1 was $2457 \mathrm{bp}$, which encoded 818 amino acid (AA) residues with the molecular weight of $93.59 \mathrm{kDa}$ and the theoretical iso-electric point (pI) of 6.05 (Figure S1). The full CDS sequence of CsRSF2 was 2466 bp, which encoded 821 AA residues with a molecular weight of $94.25 \mathrm{kDa}$ and a theoretical pI of 6.58 (Figure S2). In addition, the chromosomal distribution showed that CsRSF1 was located on chromosome 6 (scaffold00927), and CsRSF2 was located on chromosome 4 (scaffold01000) (Figure S3).

The analysis of the protein sequence showed that CsRSF1 contained an N-terminal RPW8 domain, an NB-ARC domain, and an LRR domain at the C-terminus (Figure S4A). Similarly, CsRSF2 also had an N-terminal RPW8 domain, an NB-ARC domain, and an LRR domain at the C-terminus (Figure S4B).

\subsection{Subcellular Localization and Expression Patterns of CsRSF1 and CsRSF2}

Bioinformatics prediction indicated that the CsRSF1 protein was localized in the cytoplasm and cell membrane, and the CsRSF2 protein was localized in the cytoplasm. To confirm this, the p35S:GFP-CsRSF1/CsRSF2 fusion vector was constructed (Figure 1A), and the p35S:GFP-CsRSF1/CsRSF2 and the control p35S:GFP vectors were separately introduced into tobacco leaves. Confocal microscopic examination showed that CsRSF1 and CsRSF2 proteins were both located in the cytoplasm and cell membrane. In addition, the CsRSF1 protein was also located in the nucleus (Figure 1B).

The expression patterns of CSRSF1 and CsRSF2 in different organs (leaves, cotyledons, stems and roots) of susceptible and resistant cultivars were analyzed by qRT-PCR (Figure 2). The results showed the expression patterns of CSRSF1 and CsRSF2 were different in various organs in the resistant and susceptible cultivars. Among the resistant cultivars, CsRSF1 exhibited the highest expression in roots, followed by leaves and cotyledons, but it was weakly expressed in stems (Figure 2A). Nevertheless, CsRSF1 in the susceptible cultivar was relatively highly expressed in leaves, followed by stems, roots, and cotyledons (Figure 2B). Moreover, CsRSF2 in the resistant cultivars was significantly expressed in cotyledons but barely expressed in stems, leaves, and roots (Figure 2C). In the susceptible cultivars, CsRSF2 was significantly expressed in cotyledons and stems, followed by leaves and roots (Figure 2D). This result indicated CsRSF1 and CsRSF2 genes showed varied expression patterns among organs in cucumber. The resistance of CsRSF1 and CsRSF2 may be different in various organs in the resistant and susceptible plants.

\subsection{Response of CsRSF1 and CsRSF2 to Exogenous Substances}

The transcript levels of CsRSF1 and CsRSF2 were determined in the susceptible and resistant cultivars at the two-leaf-one-heart stage after exogenous treatment with $\mathrm{ABA}$, MeJA, SA, ETH, GA, and $\mathrm{H}_{2} \mathrm{O}_{2}$ to investigate the expression patterns of CsRSF1 and CsRSF2 genes in response to exogenous substances. The result indicated that the regulation of CsRSF1 and CsRSF2 was different between resistant and susceptible varieties of cucumber after exogenous treatment with MeJA, SA, ETH, and $\mathrm{H}_{2} \mathrm{O}_{2}$. In addition, CsRSF1 and CsRSF2 may be involved in phytohormone-related signaling pathways (Figure 3). Compared with the control plants, the levels of CsRSF1 transcripts showed an upward trend at first and then a downward trend, which reached the highest level $12 \mathrm{~h}$ after ABA treatment in the resistant and susceptible cultivars (Figure 3A,B). The levels of CsRSF2 transcripts 
decreased $12 \mathrm{~h}, 24 \mathrm{~h}$, and $48 \mathrm{~h}$ after GA treatment in the resistant and susceptible cultivars (Figure 3C,D). Therefore, the results indicated that CsRSF1 might be involved in the ABA signaling pathway, while CsRSF2 might be involved in the GA signaling pathway.

A
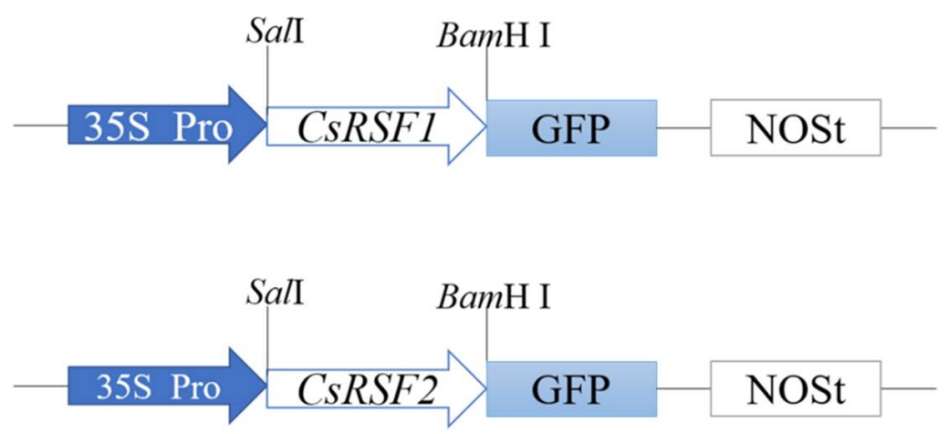

B
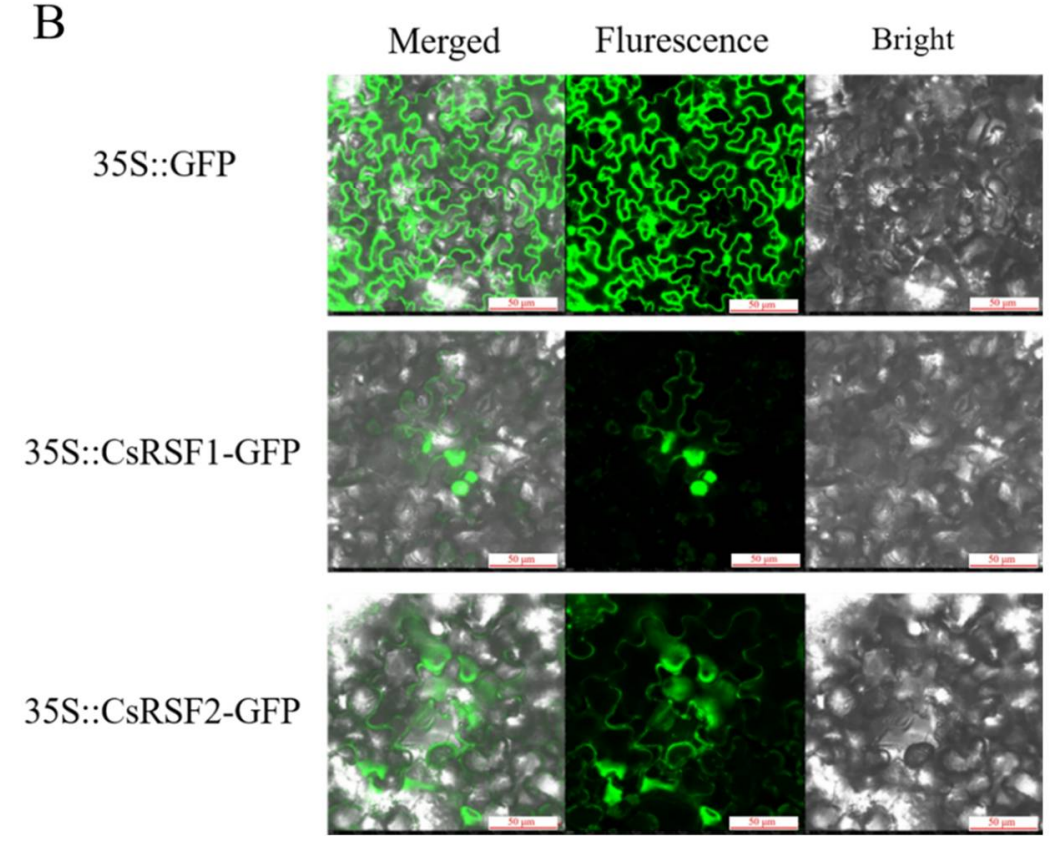

Figure 1. Subcellular localization of CsRSF1 and CsRSF2 in the Nicotiana benthamiana epidermis cell. (A) Schematic of p35S::CsRSF1-GFP and p35S::CsRSF2-GFP constructs used for the subcellular localization. (B) Green fluorescence protein (GFP) was detected in the N. benthamiana cell of the 35S::GFP, 35S::CsRSF1-GFP and 35S::CsRSF2-GFP constructs. Fluorescence, bright-field and merged images were obtained using a Leica confocal microscope. Bars $=50 \mu \mathrm{m}$.

2.4. Expression Patterns of CsRSF1 and CsRSF2 in the Resistant/Susceptible Cucumber Cultivars after S. fuliginea Inoculation

qRT-PCR was used to detect the transcription levels of CSRSF1 and CsRSF2 in the susceptible and resistant cultivars after inoculation with $S$. fuliginea (Figure 4). The comparison of the two cultivars showed that CsRSF1 expression was induced at $6 \mathrm{~h}$ and peaked at $12 \mathrm{~h}$ in the susceptible cultivar. In the resistant cultivar, CsRSF1 expression was largely induced at 3 and $6 \mathrm{~h}$. The CsRSF1 expression in the resistant cultivars were higher than that in the susceptible cultivars between $0 \mathrm{~h}$ and $9 \mathrm{~h}$ (Figure 4A). However, the CsRSF2 expression reached a peak at $3 \mathrm{~h}$ in the susceptible cultivar. CsRSF2 expression increased in the initial phase and reached a peak at $6 \mathrm{~h}$ in the resistant cultivar (Figure 4B). This finding suggested that CSRSF1 and CsRSF2 were induced upon S. fuliginea infection in the two cultivars. 
A

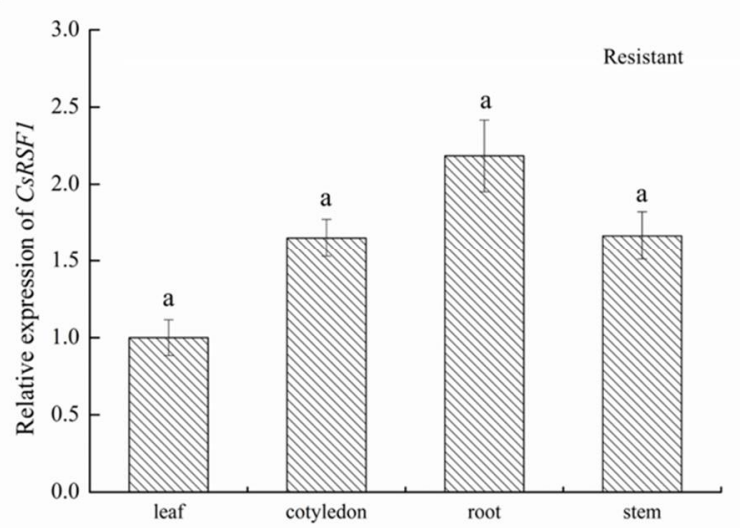

C

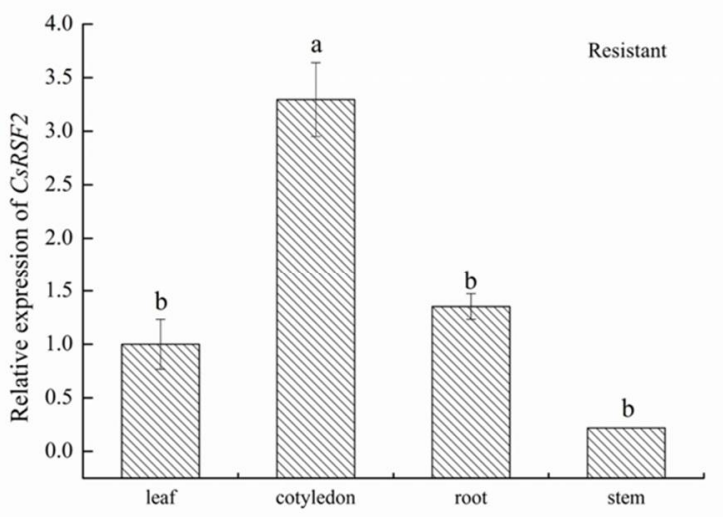

B

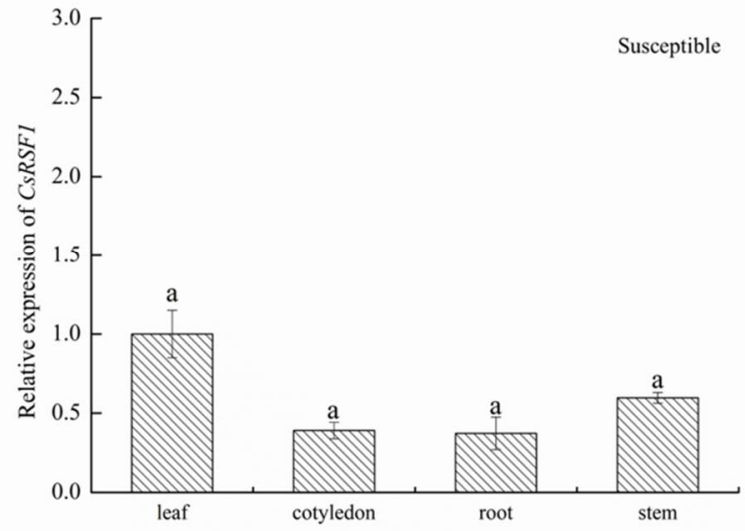

D

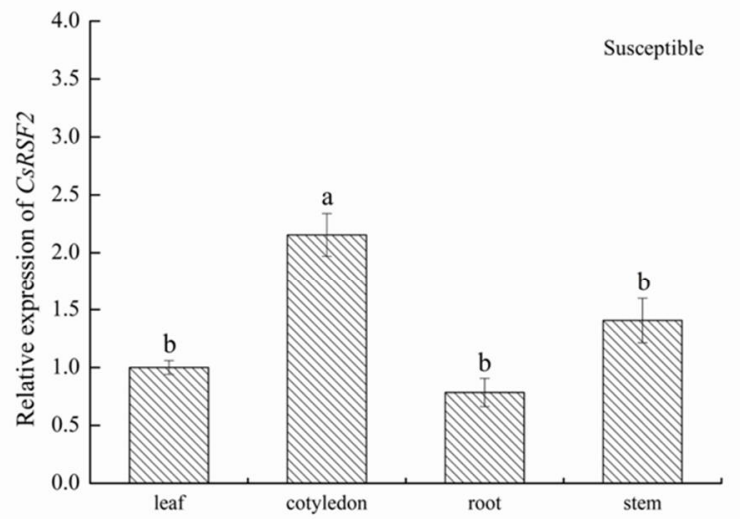

Figure 2. Expression patterns of CSRSF1 and CsRSF2 in various cucumber organs (leaf, cotyledon, stem and root). (A) Expression pattern of CsRSF1 in resistant variety. (B) Expression pattern of CsRSF1 in susceptible variety. (C) Expression pattern of CsRSF2 in resistant variety. (D) Expression pattern of CsRSF2 in susceptible variety. The expression level in the leaf was normalized as 1. Expression analysis of candidate genes using the $2^{-\Delta \Delta C t}$ method. Data are means $\pm \mathrm{SD}$ from three biological replicates per cultivar. Different letters $(a, b)$ above the bars indicate a significant difference determined by Student's $t$-test $(p<0.05)$.
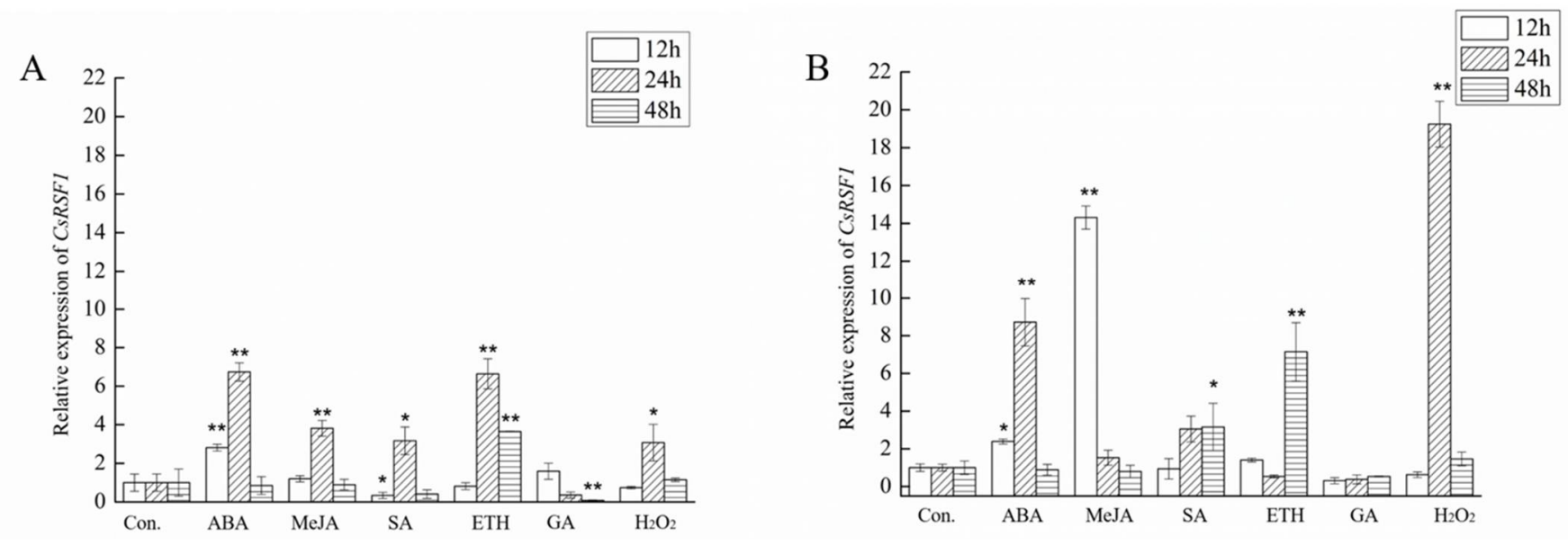

Figure 3. Cont. 

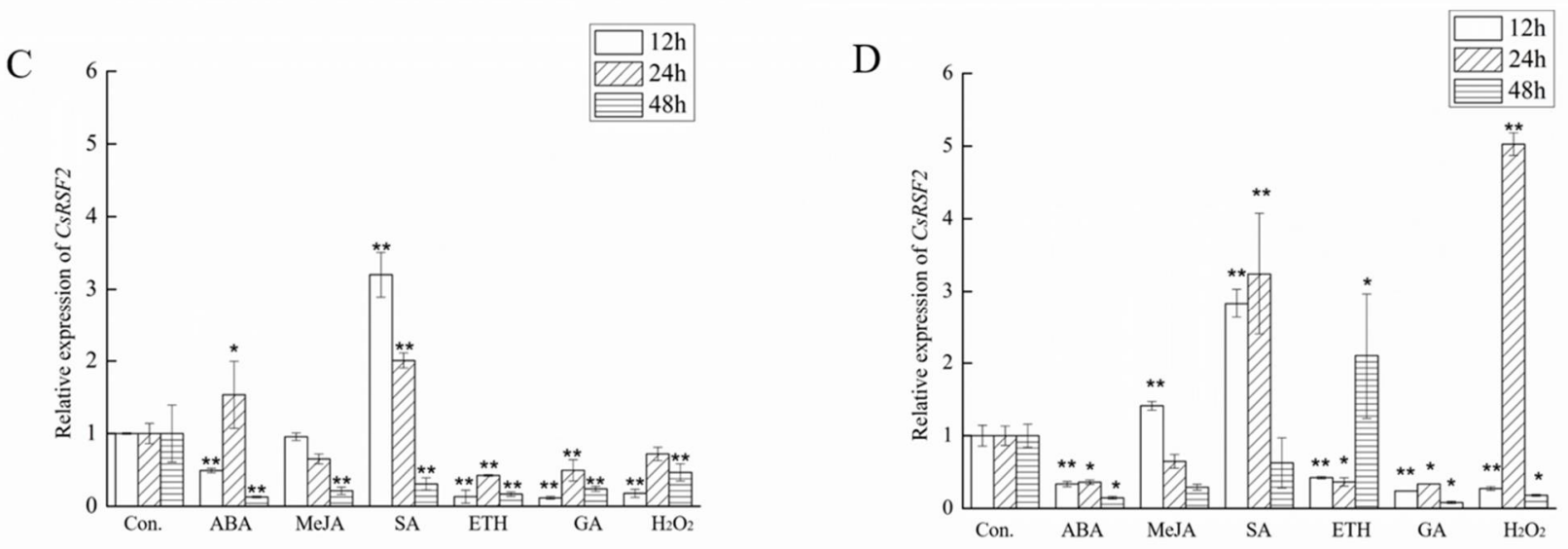

Figure 3. Expression patterns of CsRSF1 and CSRSF2 genes under exogenous substances. These exogenous substances include $100 \mu \mathrm{mol} \cdot \mathrm{L}^{-1}$ abscisic acid (ABA), $100 \mu \mathrm{mol} \cdot \mathrm{L}^{-1}$ jasmonate (MeJA), $1 \mathrm{mmol} \cdot \mathrm{L}^{-1}$ salicylic acid (SA), $10 \mu \mathrm{L} \cdot \mathrm{L}^{-1}$ ethephon $(\mathrm{ETH}), 100$ $\mathrm{mg} \cdot \mathrm{mL}^{-1}$ gibberellin (GA), $10 \mu \mathrm{mol} \cdot \mathrm{L}^{-1}$ hydrogen peroxide $\left(\mathrm{H}_{2} \mathrm{O}_{2}\right)$. (A) qRT-PCR analyses of CsRSF1 transcripts in the resistant cultivar. (B) qRT-PCR analyses of CsRSF1 transcripts in the susceptible cultivar. (C) qRT-PCR analyses of CsRSF2 transcripts in the resistant cultivar. (D) qRT-PCR analyses of CsRSF2 transcripts in the susceptible cultivar. The relative expression levels of CsRSF1 and CsRSF2 in cucumber plants at various time points $(12 \mathrm{~h}, 24 \mathrm{~h}, 48 \mathrm{~h})$ were compared with the mock control, which was set to 1. Expression analysis of candidate genes using the $2^{-\Delta \Delta C t}$ method. Data are means \pm standard deviations (SD) from three biological replicates per cultivar. The asterisks indicated a significant difference (Student's $t$-test, ${ }^{*} p<0.05$ or ${ }^{* *} p<0.01$ ).
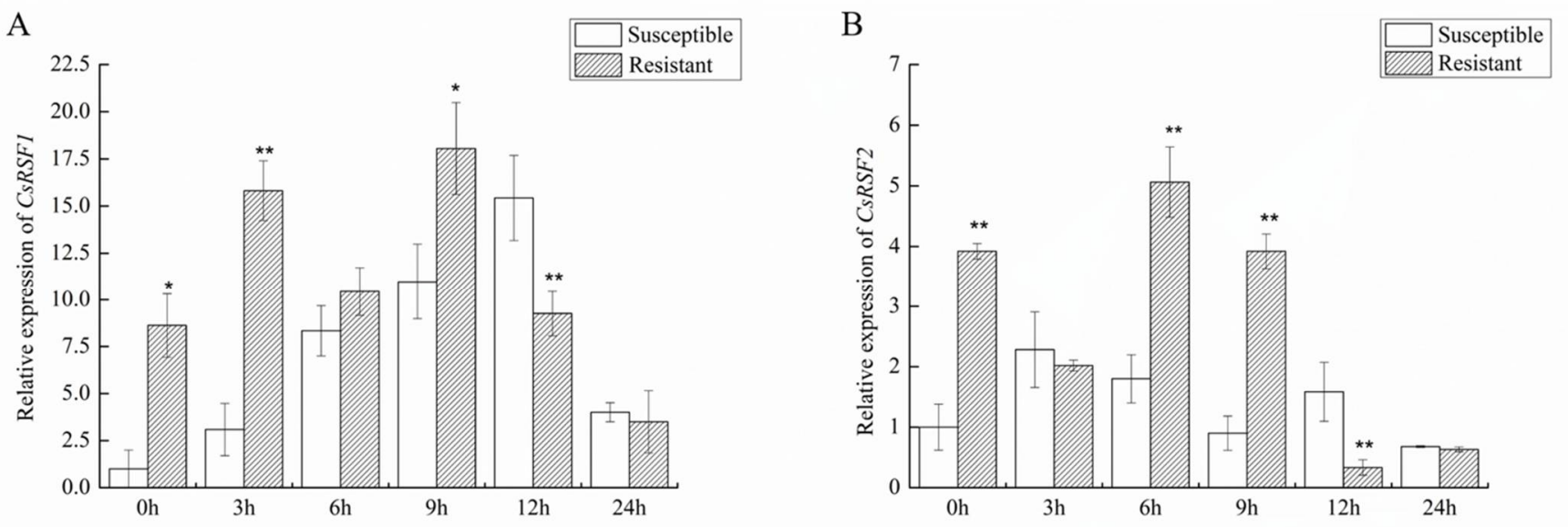

Figure 4. Expression patterns of CsRSF1 and CsRSF2 in resistant (B21-a-2-1-2) and susceptible (B21-a-2-2-2) varieties were inoculated with $S$. fuliginea. (A) The expression of CSRSF1 in resistant and susceptible varieties were inoculated with $S$. fuliginea. (B) The expression of CsRSF2 in resistant and susceptible varieties were inoculated with $S$. fuliginea. Expression analysis of candidate genes at $0,3,6,9,12$ and 24 hpi (hours post-inoculation) using the $2^{-\Delta \Delta C t}$ method. The expression level in B21-a-2-2-2 was the mock control as 1. Data are means \pm standard deviations (SD) from three biological replicates per cultivar. The asterisks indicated a significant difference (Student's $t$-test, ${ }^{*} p<0.05$ or ${ }^{* *} p<0.01$ ).

\subsection{Silencing of CsRSF1 and CsRSF2 Impairs Host Resistance to S. fuliginea}

TRV-based virus-induced gene silencing (VIGS) was used to knock down CsRSF1/ CsRSF2 transcripts in Xintaimici to explore whether CsRSF1/CsRSF2 was required for resistance of cucumber to S. fuliginea (Figure 5). A $3^{\prime}$-terminal fragment specific in CsRSF1 and a $5^{\prime}$-terminal fragment specific in CsRSF2 were inserted in the antisense orientation into the vector pTRV2, and the pTRV2:CsRSF1/CsRSF2 recombinant plasmids were generated (Figure 5A). Subsequently, TRV:CsRSF1/CsRSF2 viruses were injected into cucumber cotyledons. After inoculation with TRV:CsRSF1 or TRV: 00 (as a control) viruses for 5 days and TRV:CsRSF2 or TRV: 00 (as a control) viruses for 7 days, the mild chlorotic mosaic symptoms of TRV appeared in the cotyledons of the infected Xintaimici plants (Figure 5B). 
The TRV: 00 infections did not significantly affect the expression of CsRSF1/CsRSF2 in Xintaimici plants. Meanwhile, the transcript level of CSRSF1/CSRSF2 was markedly reduced 0.5-0.75/0.2-0.5 in TRV:CsRSF1/CsRSF2-infected (CsRSF1/CsRSF2-silencing) plants (Figure 5C). These results indicated that CsRSF1 and CsRSF2 were successfully transiently silenced in cucumber cotyledons.

A

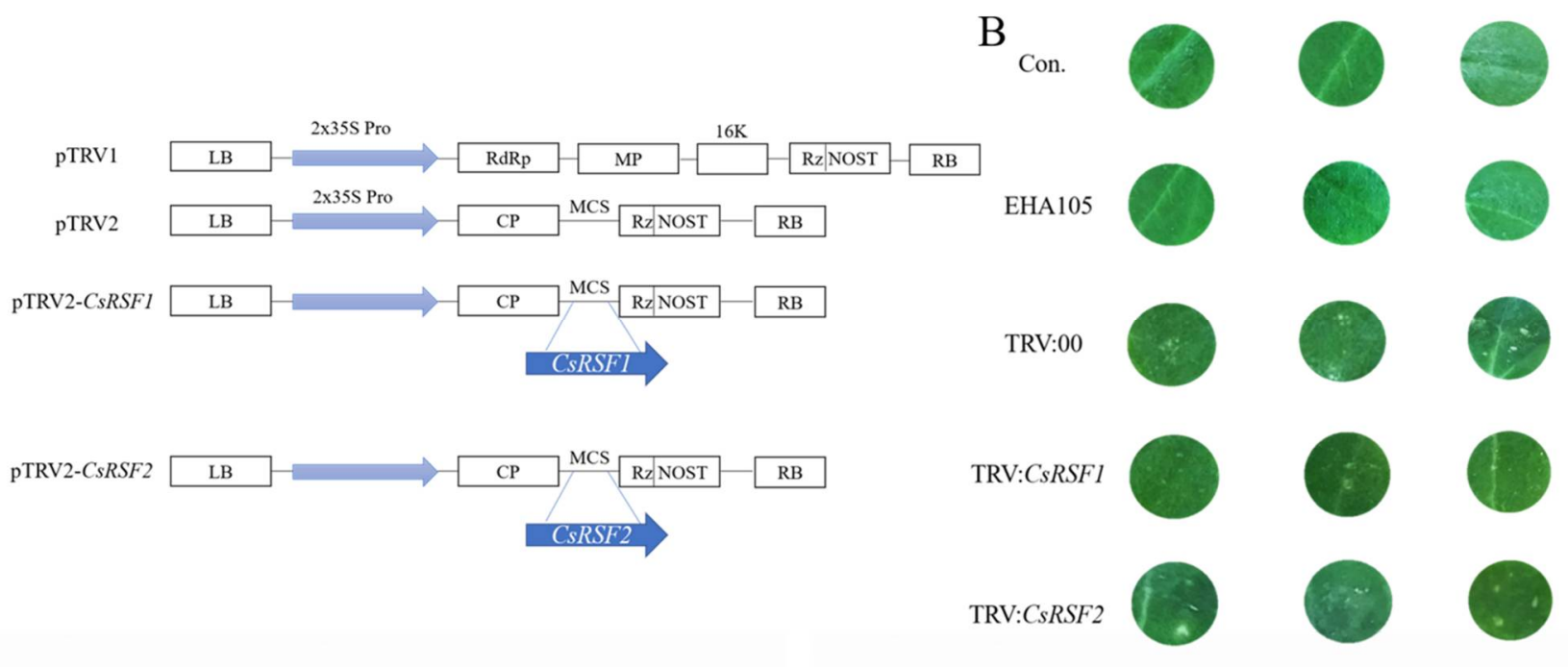

$\mathrm{C}$
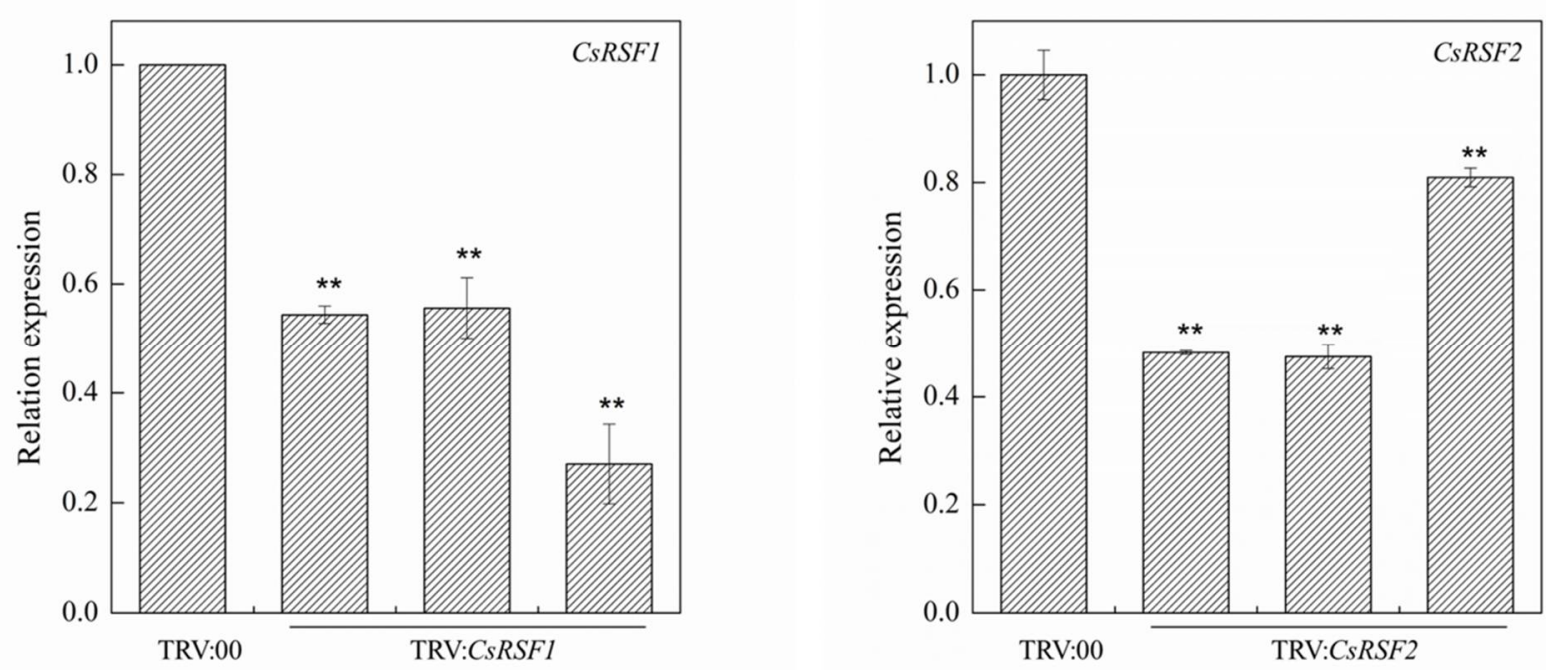

Figure 5. Identification of CsRSF1/CsRSF2-silencing cucumber plants. (A) Schematic of the CsRSF1/CsRSF2-silenced constructs. (B) Symptoms in detached cotyledons of silencing cucumber plants. Con. indicates non-injected plants. EHA105 indicates EHA105-injected plants. (C) CsRSF1/CsRSF2-silenced were identified in transgenic plants by qRT-PCR. TRV:00 indicates TRV: 00-injected plants, TRV: CSRSF1/CsRSF2 indicates silencing plants. Data are means \pm standard deviations (SD) from three independent experiments, and each column represents a sample containing three cucumber cotyledons from different plants. Expression analysis of candidate genes using the $2^{-\Delta \Delta C t}$ method. The asterisks indicated a significant difference (Student's $t$-test, ${ }^{* *} p<0.01$ ).

Further, the cotyledons of TRV-infected plants were inoculated with S. fuliginea to evaluate the defense role of CsRSF1/CsRSF2 (Figure 6). At 7 dpi with S. fuliginea, large areas of white powder (a symptom of powdery mildew disease) appeared on the cotyledons of CSRSF1/CsRSF2-silencing plants, while the areas of white powder in control and TRV: 00-treated plants (Figure 6A,B) were smaller. Moreover, many hyphae and branch spores invaded CsRSF1/CsRSF2-silencing plants, but only a few initial germ tubes and appressoria were observed in control and TRV: 00-injected cucumbers under the microscope (Figure 6A,B). In addition, the DI of the CsRSF1-silencing plants was 32.41; the DI of the 
control and TRV: 00-injected cucumbers were 22.22 and 24.44, respectively (Table 1); the DI of the CSRSF2-silencing plants was 36.11; and the DI of the control and TRV: 00-injected cucumbers was 16.68 and 17.77, respectively (Table 2). These results indicated that the silencing of CsRSF1/CsRSF2 impaired resistance to S. fuliginea, and CsRSF1 and CsRSF2 were required for the cucumber defense response to $S$. fuliginea infection.

A
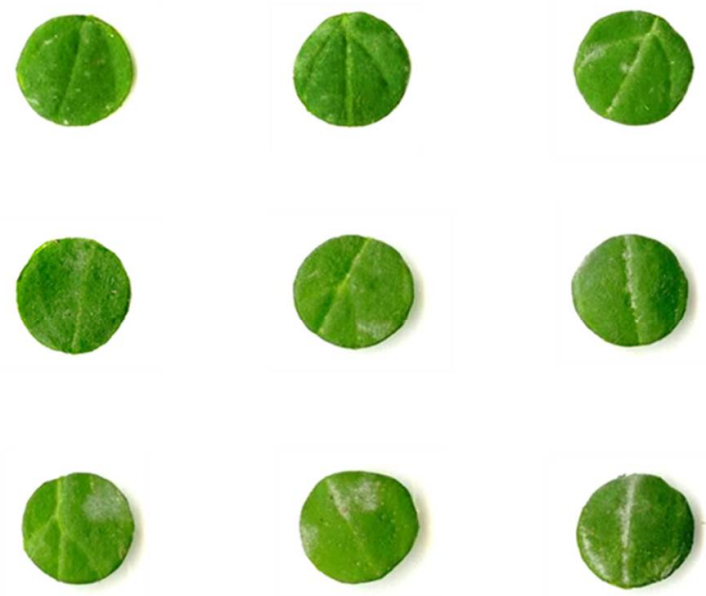

TRV:CSRSF1
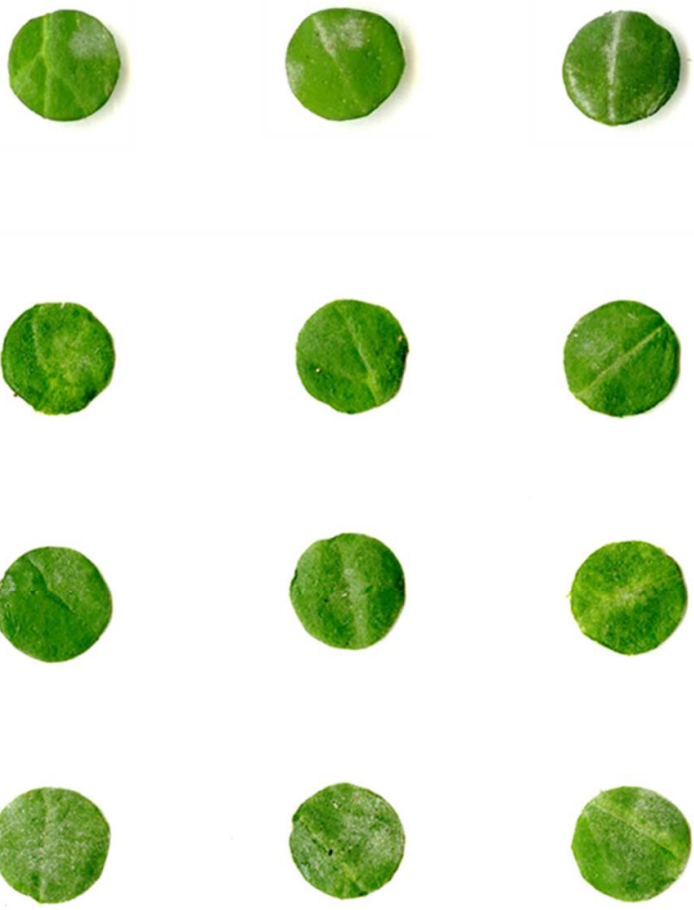

Con.

TRV:00

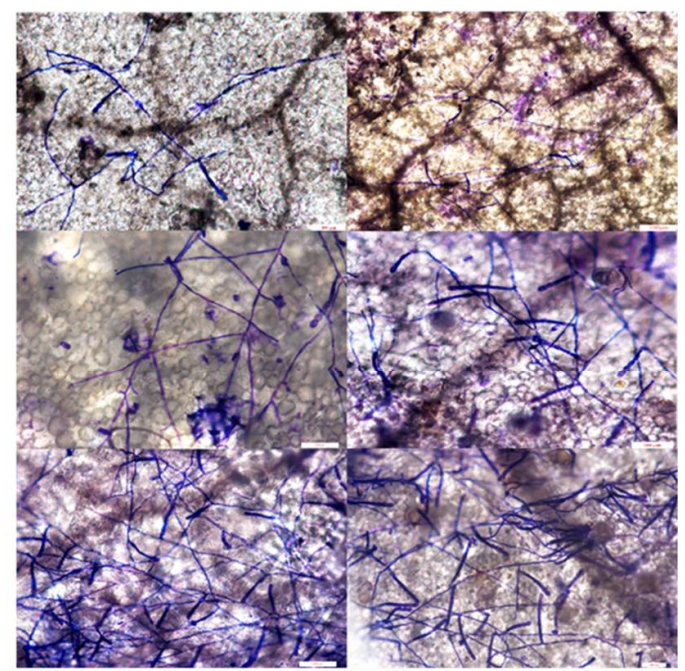

Con.

TRV:00

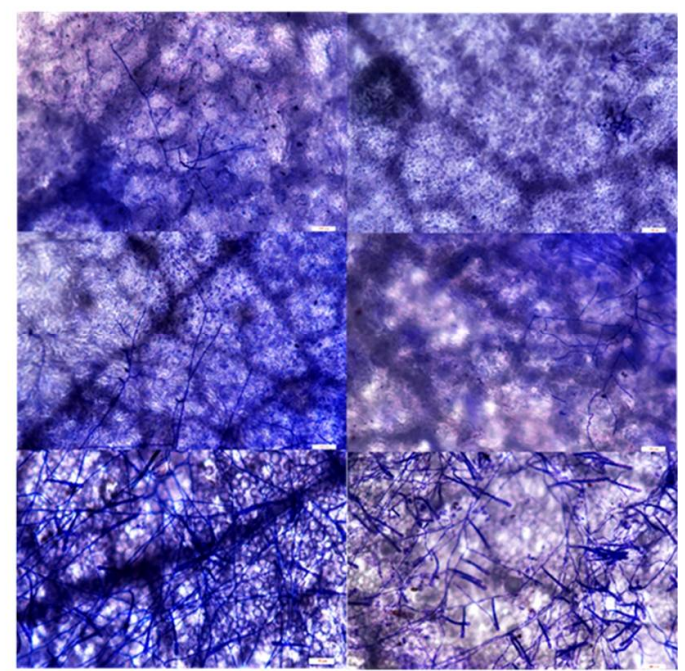

Figure 6. Identification disease-resistance of CsRSF1/CsRSF2- silencing plants after S. fuliginea infection. (A) Phenotypic analysis and Coomassie brilliant blue staining to examine CsRSF1 transient silencing cucumber cotyledons after $S$. fuliginea infection. (B) Phenotypic analysis and Coomassie brilliant blue staining to examine CsRSF2 transient silencing cucumber cotyledons after S. fuliginea infection. Con. indicates non-injected plants, TRV:00 indicates TRV:00-injected plants, TRV: CsRSF1/CsRSF2 indicates silencing plants. Bars $=100 \mu \mathrm{m}$.

Table 1. Disease index investigation for CsRSF1 transient silencing cucumber cotyledons after S. fuliginea infection.

\begin{tabular}{ccc}
\hline Material Name & Days Post-Inoculation (dpi) & Disease Index \\
\hline Con. & 7 & 22.22 \\
TRV: 00 & 7 & 24.44 \\
TRV:CSRSF1 & 7 & 32.41 \\
\hline
\end{tabular}


Table 2. Disease index investigation for CsRSF2 transient silencing cucumber cotyledons after S. fuliginea infection.

\begin{tabular}{ccc}
\hline Material Name & Days Post-Inoculation (dpi) & Disease Index \\
\hline Con. & 7 & 16.68 \\
TRV: 00 & 7 & 17.77 \\
TRV:CSRSF2 & 7 & 36.11 \\
\hline
\end{tabular}

\subsection{CSRSF1 and CsRSF2 Overexpression Improved Resistance to S. fuliginea in Cucumber}

CsRSF1/CsRSF2 was cloned into a pRI101-AN-GFP vector, and a GFP:CsRSF1/CsRSF2 plasmid was generated to further investigate whether CsRSF1/CsRSF2 was vital in cucumber disease resistance (Figure 7). The PCR analysis showed that the introduced genes could be detected in transient overexpression plants by chimeric primers between the CSRSF1/CSRSF2 and GFP fusion genes (Figure 7A). Protoplast location experiments showed that the GFP signals were detected in the CsRSF1/CsRSF2-GFP co-expression regions, confirming the success of the transient overexpression of CsRSF1/CsRSF2 in vivo (Figure 7B). In addition, the qRT-PCR assay demonstrated that the expression of the CsRSF1/CsRSF2 genes increased by 3-5.5/20-23 compared with that in the GFP: 00-injected cucumber cotyledons (Figure 7C). These results indicated that CsRSF1 and CsRSF2 were transiently overexpressed in cucumber cotyledons successfully.

A

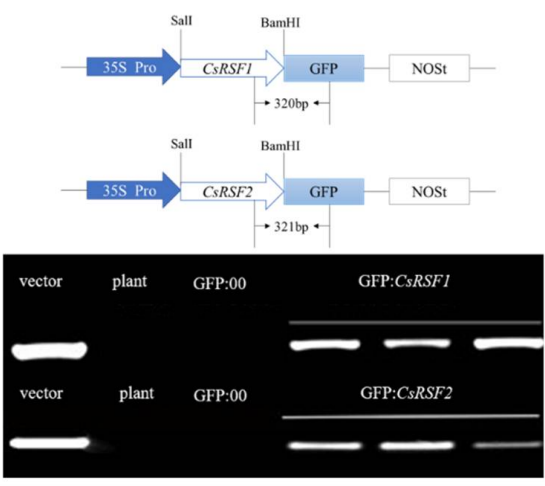

C

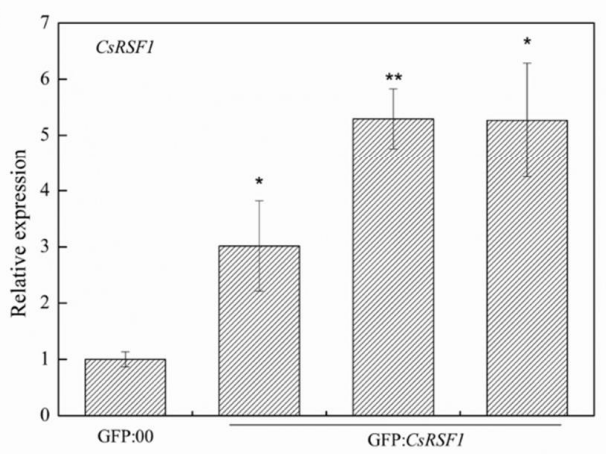

B
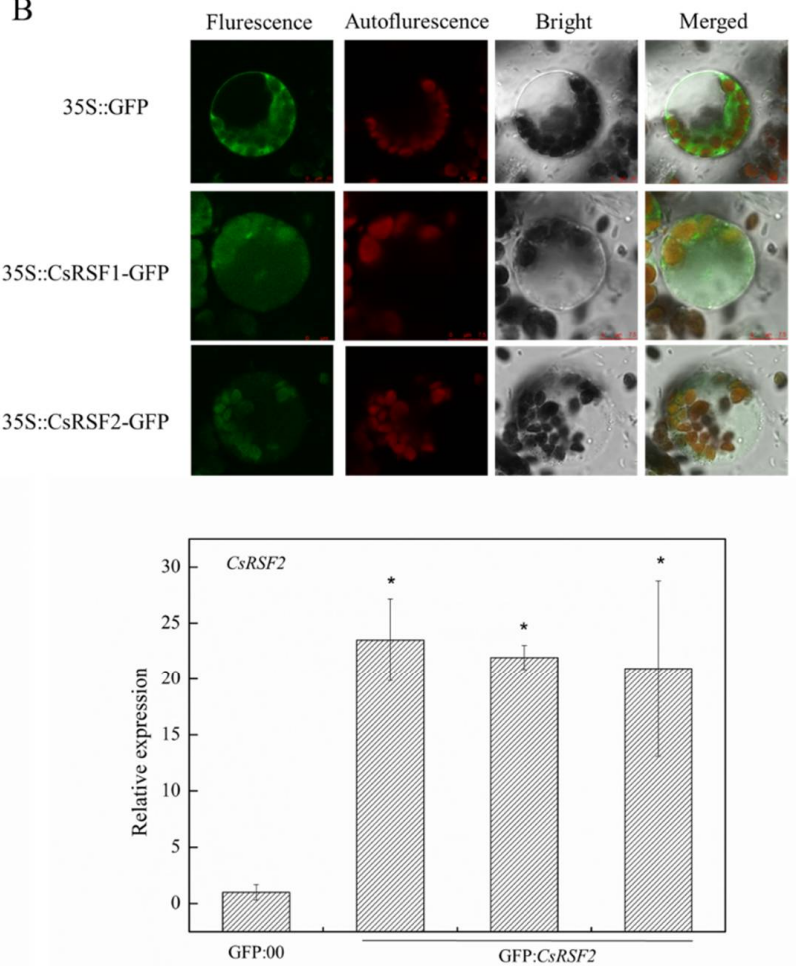

Figure 7. Identification of CsRSF1/CsRSF2-overexpressing cucumber plants. (A) Schematic of the CsRSF1/CsRSF2-GFP constructs. CsRSF1 and CSRSF2 were between 35S Pro and GFP protein, and chimeric PCR identifications of CsRSF1 and CSRSF2 genetically modified cucumber were successful. Vector, recombinant plasmid; plant, non-transgenic cucumber; GFP: 00, empty vector; GFP:CsRSF1, CsRSF1-transient overexpressing in cucumbers; GFP:CsRSF2, CsRSF2-transient overexpressing in cucumbers. (B) Luminescence signal identification for transient overexpressing cucumber cotyledons. Bar $=10 \mu \mathrm{m}$. (C) CsRSF1/CsRSF2-overexpressing were identified in transgenic plants by qRT-PCR. Data are means \pm standard deviations (SD) from three independent experiments, and each column represents a sample containing three cucumber cotyledons from different plants. Expression analysis of candidate genes using the $2^{-\Delta \Delta \mathrm{Ct}}$ method. The asterisks indicated a significant difference (Student's $t$-test, ${ }^{*} p<0.05$ or ${ }^{* *} p<0.01$ ). 
After inoculation with $S$. fuliginea, the CsRSF1/CsRSF2-overexpressing plants exhibited significantly enhanced resistance to $S$. fuliginea compared with the control and GFP: 00-injected plants (Figure 8). At $7 \mathrm{dpi}$ with $S$. fuliginea, large areas of white powder were present on the cotyledons of the control and GFP: 00-treated plants, while the areas of white powder in CsRSF1/CsRSF2-overexpressing plants were smaller (Figure 8A). Furthermore, microscopic observation indicated that the hyphae abundance of $S$. fuliginea was low on the inoculated base sheaths of the CsRSF1/CsRSF2-overexpressing plants than on the sheaths of the control and GFP: 00-injected plants (Figure 8B). The finding provided supporting evidence that CsRSF1/CsRSF2 overexpression increased resistance to hyphae development in S. fuliginea. The average disease indexes of the CsRSF1/CsRSF2-overexpressing plants infected with S. fuliginea were 24.88 and 17.33, whereas those of control and GFP: 00-injected plants were 34.59 and 32.00 (Table 3). These results indicated that CsRSF1 and CsRSF2 positively regulated cucumber resistance to powdery mildew caused by $S$. fuliginea.

A
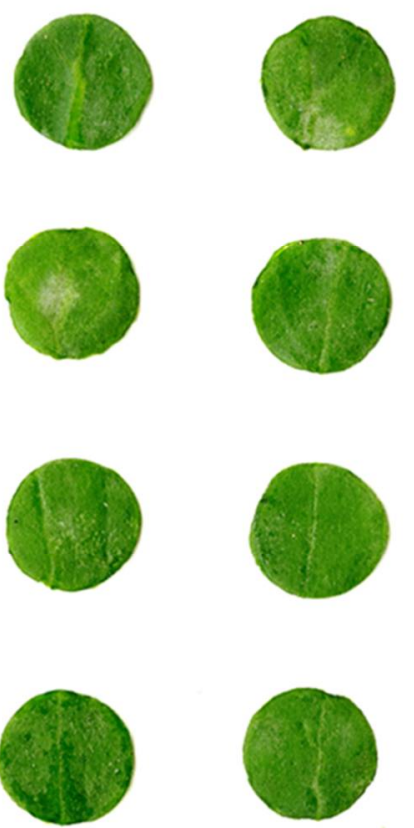

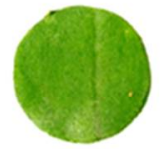

B
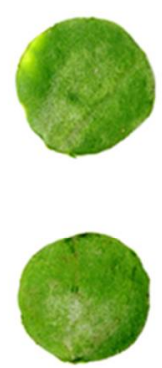

GFP:00

Con.

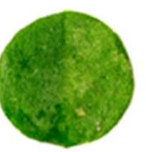

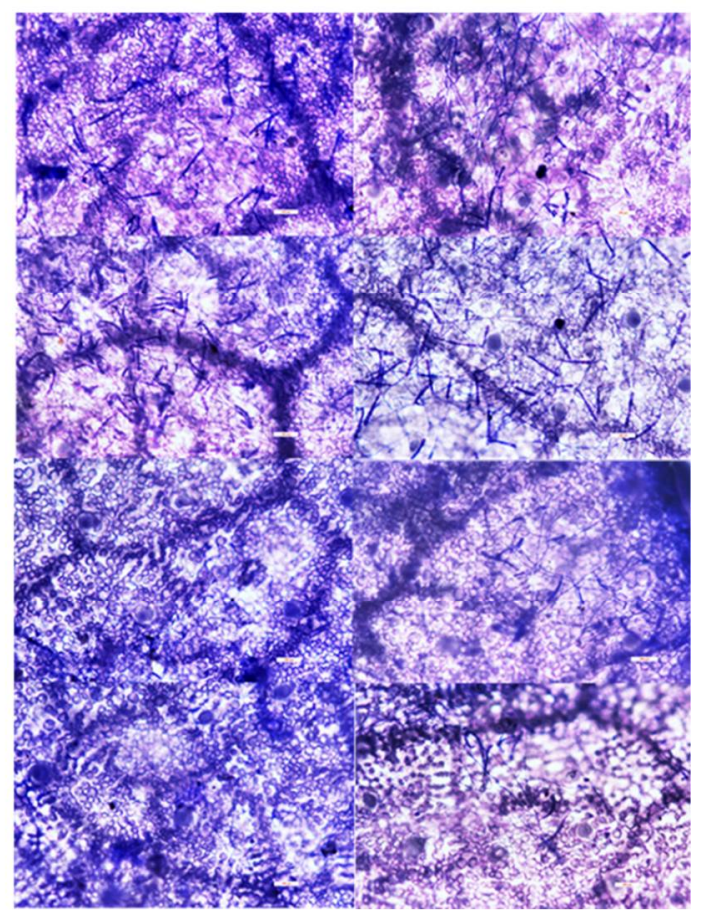

Figure 8. Identification disease-resistance of CsRSF1/CsRSF2- overexpressing plants after S. fuliginea infection. (A) Phenotypic analysis for CSRSF1 and CSRSF2 transient overexpressing cucumber cotyledons after S. fuliginea infection. (B) Coomassie brilliant blue staining for examining CSRSF1 and CsRSF2 transient overexpressing cucumber cotyledons after S. fuliginea infection. Con. indicates non-injected plants, GFP:00 indicates GFP:00-injected plants, GFP: CsRSF1/CsRSF2 indicates overexpressing plants. Bars $=100 \mu \mathrm{m}$.

Table 3. Disease index investigation for CsRSF1 and CsRSF2 transient overexpressing cucumber cotyledons after $S$. fuliginea infection.

\begin{tabular}{ccc}
\hline Material Name & Days Post-Inoculation (dpi) & Disease Index \\
\hline Con. & 7 & 34.59 \\
GFP: 00 & 7 & 32.00 \\
GFP:CSRSF1 & 7 & 24.88 \\
GFP:CSRSF2 & 7 & 17.33 \\
\hline
\end{tabular}

\subsection{CsRSF1 and CsRSF2 Modulated Expression Levels of Defense-Related Genes}

Chitinase (HM015248), CuPi1 (U93586.1), and PR-1a (AF475286) are three well-known S. fuliginea-related defense genes [33-36]. The expression patterns of the aforementioned three defense-related genes were analyzed in CsRSF1/CsRSF2-overexpressing and CsRSF1/ 
CsRSF2-silenced cucumber plants as well as the control plants to examine whether CsRSF1 and CsRSF2 regulated these defense-related genes (Figure 9). The results showed that the transcriptional levels of $C u P i 1$ and $P R-1 a$ decreased in CsRSF1-silenced plants compared with the TRV: 00-infected control plants. Simultaneously, the transcriptional level of Chitinase significantly increased, whereas the transcriptional levels of Chitinase and PR-1a increased in CsRSF1-overexpressing plants compared with GFP: 00, while the transcriptional level of $\mathrm{CuPi1}$ decreased. However, the transcriptional levels of $\mathrm{CuPi1}$ and $P R-1 a$ in CsRSF2-silenced plants were significantly higher than those in the TRV: 00-infected control plants. Only the transcriptional level of Chitinase decreased, whereas the transcriptional levels of Chitinase, CUPi1, and PR-1a significantly increased in the CsRSF2-overexpressing plants compared with GFP: 00. The results indicated that the CsRSF1/CsRSF2-induced defense pathway might be related to different defense-related genes.

A

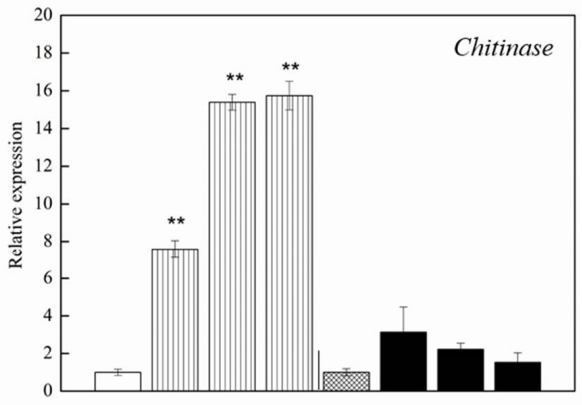

B

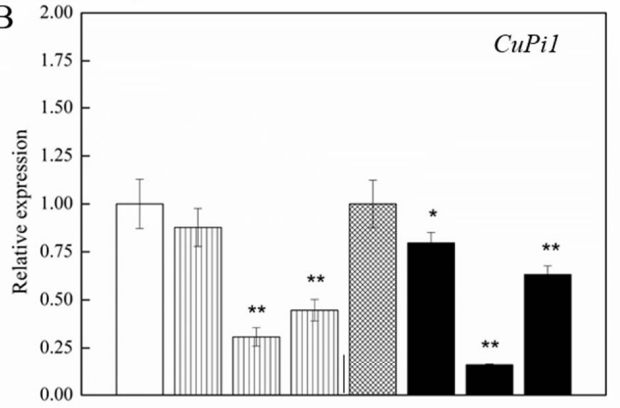

$\mathrm{C}$

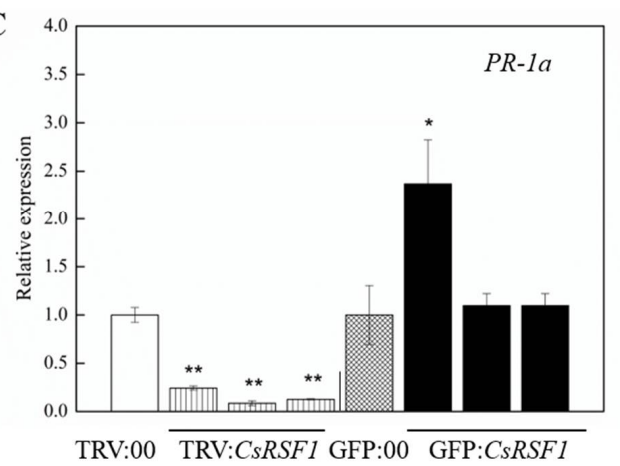

$\mathrm{D}$

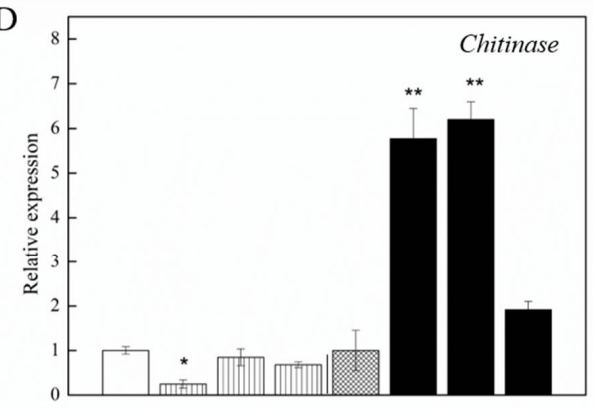

E

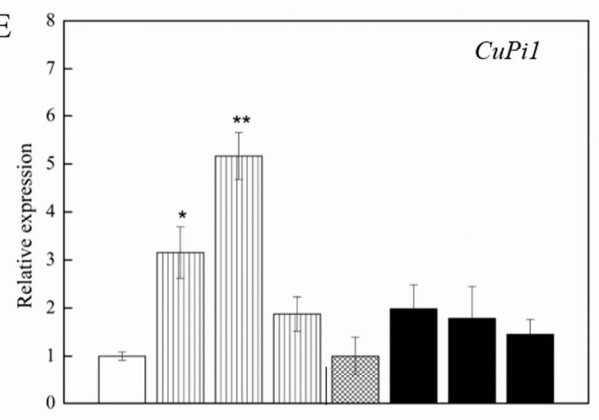

F

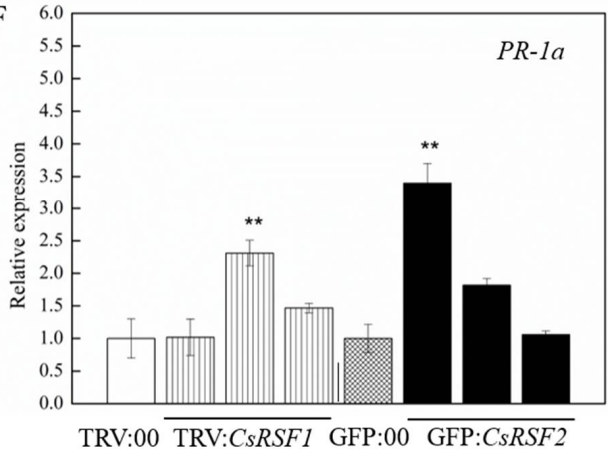

Figure 9. CsRSF1 and CSRSF2-mediated expression patterns of defense-related genes (Chitinase, CuPi1, PR-1a) in transient silencing (TRV) and overexpressing (GFP) cucumber cotyledons. (A-C) The relative expression of Chitinase, CuPi1, PR-1a in CSRSF1 -transient silencing and overexpressing cucumber cotyledons. (D-F) The relative expression of Chitinase, CuPi1, $P R-1 a$ in CSRSF2 -transient silencing and overexpressing cucumber cotyledons. Data are means \pm standard (SD) deviations from three independent experiments, and each column represents a sample containing three cucumber cotyledons from different plants. Expression analysis of candidate genes using the $2^{-\Delta \Delta C t}$ method. The asterisks indicated a significant difference (Student's $t$-test, ${ }^{*} p<0.05$ or ${ }^{* *} p<0.01$ ). 


\section{Discussion}

Powdery mildew is a common and widespread plant disease of considerable agronomic relevance. Powdery mildew outbreaks often result in severe harvest losses [37]. Cucumber powdery mildew resistance is a particularly genetically complex trait, which often involves multiple genes, but the genetic mechanisms of cucumber resistance are still poorly understood. Recently, 67 NBS-LRR resistance gene homologs have been predicted in cucumber, some of which may be related to the resistance of powdery mildew [38]. Zhang et al. [39] found four QTLs of cucumber powdery mildew, which are pm5.1, pm5.2, pm5.3, pm6.1. The pm5.2 locus has the highest contribution rate, and four NBS resistance genes (BGICucGB009775, Csa009587, Csa009605, Csa009602) were predicted in this region.

NBS-LRR is a class of proteins important in pathogen recognition and defense response signal transduction $[40,41]$. However, the role of NBS-LRR gene resistance to powdery mildew, which has been studied less and is mainly concentrated in wheat. For example, the wheat NBS-LRR gene Pm21 has broad-spectrum resistance to wheat powdery mildew [42]. However, in cucumber-S. fuliginea interactions, the role of the NBS-LRR gene is unclear. In this study, CDS regions of CsRSF1 and CsRSF2 were cloned from the cucumber leaves and their functions between cucumber-S. fuliginea interactions were identified. The expression of CsRSF1 showed a trend of increase at first and then decreased in resistant and susceptible cultivars challenged with $S$. fuliginea. The expression of CsRSF2 was different in resistant and susceptible cultivars challenged with $S$. fuliginea. In the early stage of $S$. fuliginea infection, the expression of CsRSF1 and CsRSF2 was higher in resistant cultivars than in susceptible cultivars. These results indicated that both CsRSF1 and CsRSF2 were involved in cucumber response to $S$. fuliginea infections, having a positive regulatory role.

The subcellular localization of a protein is strongly related to its biological function in plants. The NBS-LRR protein, as important intracellular receptors, can directly or indirectly recognize and interact with Avr protein products inside the cell to generate a defense response [23]. The barley CNL protein MLA10 can interact with WRKY (transcription repressor) and MYB6 (transcription activator) to activate the defense response in the nucleus [24,25]. Similarly, Arabidopsis CNL proteins RPS5, RPS2 and RPM1 recognize the pathogen effectors and interact with protein kinases and activators to generate defense response in the plasma membrane [43,44]. Therefore, the subcellular localization of NBSLRR proteins is especially important in the plant's innate immune system. In this study, the subcellular localization of 35S::CsRSF1-GFP and 35S::CsRSF2-GFP fusion proteins in tobacco epidermal cells showed that both CsRSF1 and CsRSF2 were localized in the cytoplasm and plasma membrane; mean-while, CsRSF1 was also localized in the nucleus. CsRSF1 and CsRSF2 had potential functions in various parts of the cell.

Many studies verify a gene's function by using silencing and overexpressing plants. Research showed that the tomato NBS-LRR gene SLNLC1 silences attenuated tomato resistance to Stemphylium lycopersici [45]. The overexpression and silencing of the NBSLRR gene CaRGA in chickpeas resulted in increased resistance and sensitivity to Fusarium wilt [46]. Currently, the application of stable transgenic technology to cucumber is still difficult. Hence, an experimental method was used for the transient agroinfiltration of cucumber cotyledons to obtain transient CsRSF1 and CsRSF2 silencing and overexpression plants [47]. In this study, inoculation with S. fuliginea resulted in the typical whitish appearance of powdery mildew disease on CSRSF1 and CsRSF2 silencing plants and also caused them to exhibit greater hyphal abundances and a lower DI than control plants. This result is contrary to CsRSF1 and CsRSF2 overexpression plants. The functional analysis showed that CsRSF1 and CsRSF2 overexpression significantly increased the resistance of cucumber to $S$. fuliginea, while CSRSF1 and CsRSF2 silencing significantly compromised resistance to $S$. fuliginea.

Different regulatory proteins might activate different kinds of genes in cucumber defense response to $S$. fuliginea [34]. Chitinase has a positive regulatory effect on the resistance of cucumber to S. fuliginea. SA signaling pathway induces PR gene expression, which can enhance resistance to a broad range of pathogens [48]. Therefore, PR gene 
expression is a sign of plant disease resistance. $P R-1 a$ is one of the PR genes. In this study, the expression of $P R-1 a$ was lower on CsRSF1 silencing plants than control plants, higher on CsRSF1 overexpression plants than control plants. The expression of Chitinase was lower on CsRSF2 silencing plants than control plants, higher on CsRSF2 overexpression plants than control plants. CsRSF1 positively modulated the expression of $P R-1 a$, while CsRSF2 positively modulated the expression of Chitinase.

Plant hormones are essential for plants to respond to biological and abiotic stresses. They are important signal molecules that can participate in the regulation of plant defense signal transduction pathway and plant defense gene expression $[49,50]$. Several studies have shown that plant hormone are involved in the NBS-LRR protein-mediated defense responses [51].

$\mathrm{ABA}$ is a positive or negative regulator in the process of plant defense against various pathogens [52,53]. Exogenous application of ABA enhances rice resistance to Cochliobolus miyabeanus [54]. In addition, the application of ABA increases the susceptibility of Arabidopsis plants to Pseudomonas syringae [55]. JA helps to regulate the plant defense response to insect and microbial pathogens [56]. Niu [57] pointed out that JA was a signal molecule involved in wheat powdery mildew resistance. Exogenous application of MeJA to Arabidopsis thaliana helps protect it against gray mold [58,59]. SA is vital in plant defense; it is one of the key signaling molecules involved in activating pathogen resistance [60,61]. The Arabidopsis NBS-LRR gene RRS1-R-mediated resistance to Ralstonia solanacearum depends on SA. Plant infection by pathogens can promote ET production and in turn induce the expression of a series of genes related to the disease course [62,63]. ET signaling also interacts with JA and SA signaling pathways to help plants resist the invasion of pathogenic bacteria [64-67]. The RCY1 gene, which encodes the Arabidopsis CC-NBS-LRR protein to confer resistance to the cucumber mosaic virus, requires SA and ET signal transduction mechanisms [68]. GA promotes plant growth by stimulating the degradation of the negative growth regulator DELLA protein. DELLA protein controls the plant's immune response by regulating the balance of JA and SA signals, indicating that GA is essential in response to pathogens' invasion [69]. Reactive oxygen species (ROS) production is excessive in the early stages of plant-pathogen interactions. Appropriate levels of ROS can not only promote cell wall enhancement and plant antitoxin production but also have a signaling role in plant defense responses [70]. ROS signaling is involved in the resistance of transgenic cotton (expressing endochitinase gene) to Rhizoctonia solani [71]. The wheat NBS-LRR gene TaRCR1 maintains ROS's stability by regulating the transcription of ROS-scavenging enzyme gene CAT1 and peroxidase gene POX2. TaRCR1 then regulates the expression of defense-related genes to enhance the resistance to Rhizoctonia cerealis [70]. In this study, cucumber leaves were sprayed with different exogenous substances, such as ABA, MeJA, SA, ETH, GA, and $\mathrm{H}_{2} \mathrm{O}_{2}$. The qRT-PCR analysis showed that both CsRSF1 and CsRSF2 genes could be induced and expressed to different degrees. These results suggested that CsRSF1 and CsRSF2 may be involved in the crosstalk of exogenous substances against $S$. fuliginea. In addition, the expression of the CsRSF1 gene was upregulated and then downregulated at all treatment time points and reached the peak $12 \mathrm{~h}$ after ABA treatment. After GA treatment, the expression of the CSRSF2 gene was downregulated at all treatment time points. The results indicated that CSRSF1 might be associated with the ABA signaling pathway in defense responses. CSRSF2 might be involved in defense responses of the GA signaling pathway. However, their mechanism of action is currently unclear.

The rice NBS-LRR resistance protein Pit interacts with the GEF OsSPK1 to activate OsRac1 and trigger rice immunity [72]. The Gossypium hirsutum NBS-LRR gene GhDSC1 modulates defense responses of ROS accumulation and expression of JA-regulated defense genes [73]. By now, the regulatory mechanisms of NBS-LRR gene resistance to powdery mildew and it activates the defense response by which signaling pathway are unclear, especially in cucumber. Our study lay a foundation for exploring regulatory mechanisms of NBS-LRR gene resistance to powdery mildew in cucumber. 


\section{Materials and Methods}

\subsection{Plant Materials and Treatments}

Cucumber B21-a-2-2-2 (highly susceptible to S. fuliginea), B21-a-2-1-2 (highly resistant to $S$. fuliginea) and XinTaiMiCi were used in this study for gene transformation. B21-a-22-2 and B21-a-2-1-2 are two sister lines. Cucumber plants were grown in a room with a day/night temperature of $25^{\circ} \mathrm{C} / 22^{\circ} \mathrm{C}$ and a $16 \mathrm{~h}$ light photoperiod.

\subsection{Pathogen Growth and Inoculation}

S. fuliginea was collected from the naturally infected cucumber plants of the Vegetable Institute of the Liaoning Academy of Agricultural Sciences (Shenyang, China). The pathogen was cultured on leaves of potted cucumber and amplified at $25^{\circ} \mathrm{C}$ in the laboratory. Spores of $S$. fuliginea were harvested from highly infected cucumber leaves by washing leaves with sterile water containing $10 \mu \mathrm{g} \cdot \mathrm{mL}^{-1}$ SDS and filtering with sterile gauze. The spore concentration was adjusted to $30-40$ spores per field of vision $(10 \times 10$ times under microscope). Then the spore suspension was sprayed evenly on cucumber leaves without S. fuliginea using a throat sprayer [74].

\subsection{Full-Length CDS Cloning and Sequence Analysis}

Primers (F and R) were designed according to the sequences of the target genes found on the Phytozome database (https:/ / phytozome.jgi.doe.gov/pz/portal.html, accessed on 16 July 2018). Primer design was conducted using Primer 5 software (Premier, Mississauga, Ontario, Canada). The gene-specific primers are listed in Table S1. Total RNA was extracted from the leaves of B21-a-2-1-2 and B21-a-2-2-2 using an RNAprep pure plant kit (Tiangen Biotech, Beijing, China) and synthesized into cDNA using the FastQuant cDNA (Tiangen Biotech, Beijing, China). The following PCR program was used: $98^{\circ} \mathrm{C}(10 \mathrm{~s}), 56^{\circ} \mathrm{C}(15 \mathrm{~s})$, and $68{ }^{\circ} \mathrm{C}(3 \mathrm{~min})$ for 35 cycles. The reaction was conducted in a $20 \mu \mathrm{L}$ volume containing $5 \mu \mathrm{L}$ of $5 \times$ PrimeSTAR GXL buffer, $2 \mu \mathrm{L}$ of dNTP mixture, $0.5 \mu \mathrm{L}$ of each primer, $2 \mu \mathrm{L}$ of genomic DNA, $0.5 \mu \mathrm{L}$ of PrimeSTAR GXL DNA polymerase, and $8.5 \mu \mathrm{L}$ of doubly distilled water. DNAMAN software (Lynnon Biosoft, San Ramon, CA, USA) was used for sequence alignment. Bioinformatics software was used for sequence analysis.

\subsection{Subcellular Localization}

The coding regions of CsRSF1 and CsRSF2 were amplified using PrimeSTAR GXL DNA polymerase (Takara, Dalian, China). The PCR amplification procedure was as follows: $98{ }^{\circ} \mathrm{C}(10 \mathrm{~s}), 56{ }^{\circ} \mathrm{C}(15 \mathrm{~s})$, and $68^{\circ} \mathrm{C}(3 \mathrm{~min})$ for 35 cycles. The PCR products were detected by agarose gel electrophoresis and ligated to the $3^{\prime}$ end of the GFP coding region without the stop codon in the p35S:GFP vector, generating the fusion constructs p35S:GFPCsRSF1 and p35S:GFP-CsRSF2. The recombinant plasmids p35S:GFP-CsRSF1, p35S:GFPCSRSF2, and p35S:GFP were separately transformed into Agrobacterium tumefaciens strain EHA105 and then centrifuged after overnight culture. The precipitate after centrifugation was cultured in induction medium $\left(10 \mathrm{mmol} \cdot \mathrm{L}^{-1} 2\right.$-(4-morpholino) ethanesulfonic acid (MES), $\mathrm{pH} 5.7,10 \mathrm{mmol} \cdot \mathrm{L}^{-1} \mathrm{MgCl} 2$ and $200 \mathrm{mmol} \cdot \mathrm{L}^{-1}$ acetosyringone (AS)), collected and diluted to $\mathrm{OD}_{600}=0.6$, and then infiltrated into Nicotiana benthamiana leaves. The plants were incubated at $25^{\circ} \mathrm{C}$ for 3 days after injection, and point GFP signals were observed and photographed using a laser confocal fluorescence microscope (Leica, TSC SP8, Solms, Germany) with an excitation wavelength of $488 \mathrm{~nm}$ and 505 to $530 \mathrm{~nm}$ bandpass emission filter.

\subsection{Abiotic and Biotic Stresses}

1-month-old and 9-day-old cucumber seedlings (B21-a-2-1-2 and B21-a-2-2-2) were used in the following treatments. The leaves of 1-month-old cucumber seedlings were sprayed with $100 \mu \mathrm{mol} \cdot \mathrm{L}^{-1} \mathrm{ABA}, 100 \mu \mathrm{mol} \cdot \mathrm{L}^{-1} \mathrm{MeJA}, 1 \mathrm{mmol} \cdot \mathrm{L}^{-1} \mathrm{SA}, 10 \mu \mathrm{L} \cdot \mathrm{L}^{-1} \mathrm{ETH}$, $100 \mathrm{mg} \cdot \mathrm{mL}^{-1} \mathrm{GA}$, and $10 \mu \mathrm{mol} \cdot \mathrm{L}^{-1} \mathrm{H}_{2} \mathrm{O}_{2}$ to simulate abiotic stress, while control seedlings were sprayed with distilled water. The cotyledons of 9-day-old cucumber seedlings were 
sprayed with S. fuliginea to simulate biotic stress, while control seedlings were sprayed with distilled water. The leaves of the abiotic stress/biotic stress-treated seedlings were harvested at indicated time points $(12 \mathrm{~h}, 24 \mathrm{~h}$, and $48 \mathrm{~h}$ and $0 \mathrm{~h}, 3 \mathrm{~h}, 6 \mathrm{~h}, 9 \mathrm{~h}, 12 \mathrm{~h}$, and $24 \mathrm{~h}$, respectively), frozen in liquid nitrogen, and then stored at $-80^{\circ} \mathrm{C}$ until further use.

\subsection{Tobacco Rattle Virus (TRV)-Mediated CsRSF1/CsRSF2 Gene Silencing}

The pTRV2:CSRSF1 and pTRV2:CSRSF2 recombinant constructs were generated by subcloning a $233 \mathrm{bp}$-specific fragment within the $3^{\prime}$ region of the sequence of CsRSF1 (from 2225 to 2457 nucleotides in CsRSF1 CDS sequence) and a 289 bp-specific fragment within the $5^{\prime}$ region of the sequence of CsRSF1 (from 1 to 289 nucleotides in CsRSF1 CDS sequence) in the antisense orientation into the PTRV2. The gene-specific primers are listed in Table S1. Then, the pTRV2:CsRSF1 and pTRV2:CsRSF2 recombinant constructs were introduced into different $A$. tumefaciens EHA105 aliquots. A $12.5 \mathrm{~mL}$ culture of different A. tumefaciens (pTRV2:CsRSF1, pTRV2:CsRSF2, and pTRV2, pTRV1) strains were grown overnight at $28^{\circ} \mathrm{C}$ in the YEP medium supplemented with $50 \mathrm{mg} \cdot \mathrm{L}^{-1}$ of rifampicin and $50 \mathrm{mg} \cdot \mathrm{L}^{-1}$ of kanamycin. Then, each $100 \mu \mathrm{L}$ overnight culture was inoculated into $12.5 \mathrm{~mL}$ portions of the YEP medium with the aforementioned antibiotics and cultivated at $28^{\circ} \mathrm{C}$ until the culture reached selected optical densities of $\mathrm{OD}_{600}=0.8-1.0$. The samples were supplemented with $10 \mathrm{mmol} \cdot \mathrm{L}^{-1} \mathrm{MES}, 10 \mathrm{mmol} \cdot \mathrm{L}^{-1} \mathrm{MgCl}_{2}$, and $200 \mu \mathrm{mol} \cdot \mathrm{L}^{-1}$ AS until the $\mathrm{OD}_{600}=0.4$ for each construct. The induced A. tumefaciens EHA105 strains carrying different pTRV2-derived vectors (pTRV2, pTRV2:CsRSF1, and pTRV2:CsRSF2) were mixed with the PTRV1 A. tumefaciens strain EHA105 in a ratio of 1:1. Then, the samples were co-infiltrated into fully expanded cotyledons of cucumber plants using a $1 \mathrm{~mL}$ syringe. The plants were placed in a room at $22{ }^{\circ} \mathrm{C}$ with a $16 \mathrm{~h}$ light and $8 \mathrm{~h}$ dark photoperiod for growth.

\subsection{CsRSF1 and CsRSF2 Overexpression Transformation}

The full CDS sequences of the CsRSF1 and CsRSF2 genes were subcloned into a modified pRI101-AN-GFP vector with a GFP tag, resulting in the transformation vector pRI101-AN-GFP:CsRSF1 and pRI101-AN-GFP:CsRSF2. The cloning site was between BamHI and SalI. The gene-specific primers are listed in Table S1. The constructed vectors and pRI101-AN-GFP were transformed into A. tumefaciens strain EHA105. The transformation method was the same as described earlier.

\subsection{Quantitative Reverse-Transcription PCR ( $q R T-P C R$ )}

Total RNA was extracted from cucumber euphylla, and cotyledons using an RNAprep pure plant kit (Tiangen Biotech, Beijing, China) and was used for cDNA synthesis using a fasting RT Kit cDNA (Tiangen Biotech, Beijing, China). The primers were designed using Primer 5 software (Premier, Mississauga, ON, Canada), and the PCR reaction quality was estimated based on melting curves. Three biological replicates of cDNA were used for three repeated experiments. The actin gene of cucumber was used as the internal reference. Quantitative reverse-transcription PCR (qRT-PCR) was used to detect the transcription level of CsRSFs under different treatments using the SYBR Green I 96-I system (Roche fluorescence quantitative PCR instrument, Basel, Switzerland). The reaction mixtures consisted of $4.5 \mu \mathrm{L}$ of $2 \times$ SuperReal PreMix Plus (Tiangen Biotech, Beijing, China), $0.2 \mu \mathrm{L}$ of primers ( $0.1 \mu \mathrm{L}$ of the forward primer and $0.1 \mu \mathrm{L}$ of reverse primer), $4.3 \mu \mathrm{L}$ of RNase-free $\mathrm{ddH}_{2} \mathrm{O}$, and $1 \mu \mathrm{L}$ of cDNA. The PCR program was set up in seven stages: (1) $95^{\circ} \mathrm{C}$ for $15 \mathrm{~min}$ (pre-incubation), (2) $95^{\circ} \mathrm{C}$ for $10 \mathrm{~s}$, (3) $58^{\circ} \mathrm{C}$ for $20 \mathrm{~s}$, (4) $72{ }^{\circ} \mathrm{C}$ for $30 \mathrm{~s}$, (3) repeated 40 times (amplification), (5) $95^{\circ} \mathrm{C}$ for $0.5 \mathrm{~s},(6) 60^{\circ} \mathrm{C}$ for $1 \mathrm{~min}$ and (melt), and (7) $50{ }^{\circ} \mathrm{C}$ for $30 \mathrm{~s}$ (cooling). The relative expression levels of the target genes were calculated using the $2^{-\Delta \Delta C t}$ method. The significance was determined by the Student's $t$-test $(p<0.05$ or $p<0.01$ ) using SPSS statistical software (SPSS 22.0, Nlinedown, Guangdong, China). All the primers are listed in (Table S2). 


\subsection{Extraction of Cucumber Protoplasts}

The cucumber cotyledons transformed with recombinant vectors were cut into 0.5 to $1 \mathrm{~mm}$ thin strips, quickly transferred to the enzymatic hydrolysate $\left[20 \mathrm{mmol} \cdot \mathrm{L}^{-1} \mathrm{MES}\right.$, $1.5 \%$ cellulase R-10, $0.4 \%$ macerozyme R-10, $20 \mathrm{mmol} \cdot \mathrm{L}^{-1} \mathrm{KCl}, 0.4 \mathrm{~mol} \cdot \mathrm{L}^{-1}$ mannitol, $10 \mathrm{mmol} \cdot \mathrm{L}^{-1} \mathrm{CaCl}_{2}$, and $0.1 \%$ bovine serum albumin (BSA), $\mathrm{pH}$ 5.7], and shaken at $50 \mathrm{rpm}$ for $6 \mathrm{~h}$ after $30 \mathrm{~min}$ of vacuum infiltration. The enzymatic hydrolysate was diluted with an equal amount of W5 $\left(0.2 \mathrm{~mol} \cdot \mathrm{L}^{-1} \mathrm{MES}, 1.54 \mathrm{~mol} \cdot \mathrm{L}^{-1} \mathrm{NaCl}, 1 \mathrm{~mol} \cdot \mathrm{L}^{-1} \mathrm{CaCl}_{2}\right.$, and $0.2 \mathrm{~mol} \cdot \mathrm{L}^{-1} \mathrm{KCl}, \mathrm{pH}$ 5.7) and filtered through a $200 \mathrm{~mm}$ nylon membrane. The filtered solution was centrifuged at $100 \times g$ and $4{ }^{\circ} \mathrm{C}$ for $2 \mathrm{~min}$. The supernatant was gently removed with a pipette. The remaining green liquid, which contained protoplasts, was placed on the ice for $30 \mathrm{~min}$. Finally, the protoplasts were resuspended in the same volume of pre-cooled MMG $\left(0.2 \mathrm{~mol} \cdot \mathrm{L}^{-1} \mathrm{MES}, 0.4 \mathrm{~mol} \cdot \mathrm{L}^{-1}\right.$ mannitol, and $\left.1.5 \mathrm{~mol} \cdot \mathrm{L}^{-1} \mathrm{MgCl}_{2}\right)$ and then observed under a laser fluorescence microscope (Leica, TSC SP8, Solms, Germany).

\subsection{Coomassie Brilliant Blue R250 Staining and Microscopy}

Coomassie brilliant blue R250 staining was used to observe the $S$. fuliginea hyphae on the cotyledons with the control of TRV:00, TRV:CsRSF1, TRV:CsRSF2, GFP: 00, GFP:CsRSF1, and GFP:CsRSF2 transgenic plants on day 7 with $S$. fuliginea. The infected cotyledons of control and transgenic plants were immersed in a destaining solution (containing $0.225 \mathrm{~g}$ trichloroacetic acid, $150 \mathrm{~mL}$ of absolute ethanol, and $50 \mathrm{~mL}$ of acetone) for $30 \mathrm{~min}$ at $70{ }^{\circ} \mathrm{C}$. The samples were then stained with Coomassie brilliant blue R250 solution (containing $0.225 \mathrm{~g}$ trichloroacetic acid, $0.9 \mathrm{~g}$ Coomassie brilliant blue R250, and $150 \mathrm{~mL}$ of methanol) for $2 \mathrm{~min}$ at room temperature. After the samples were washed with sterile water, they were immersed in $20 \%$ glycerol and photographed. The fungus was visualized under a light microscope (Nikon Ts2, Tokyo, Japan).

\subsection{Disease Index}

The typical symptoms of pathogen whiteness were measured in six disease severity ratings from 0 to 9 , where 0 denoted no symptom, 1 denoted white lesions accounting for less than $5 \%$ of the entire inoculated leaves, 3 denoted white lesions accounting for $5 \%-25 \%$ of the entire inoculated leaves, 5 denoted white lesions accounting for $26 \%-50 \%$ of the entire inoculated leaves, 7 denoted white lesions accounting for $51 \%-75 \%$ of the entire inoculated leaves, and 9 denoted white lesions accounting for more than $75 \%$ of the entire inoculated leaves. Disease index (DI) was calculated using the following formula: DI $(\%)=[(N \times D) /(H \times T)] \times 100$, where $N$ is the number of leaves with the respective disease rating, $D$ is the disease rating, $H$ is the highest disease rating, and $T$ is the total number of observed leaves [75]. No fewer than 60 cucumber leaves were surveyed for the DI evaluation.

\subsection{Data Processing and Statistical Analysis}

Data were the mean \pm standard deviation of three biological replicates per cultivar. The $2^{-\Delta \Delta C t}$ method was used to calculate the relative expression levels of the target genes. Standard errors of deviation were assessed using the STDEVA function in Excel. Statistical significance was analyzed using the Student's $t$-test $(p<0.05$ or $p<0.01)$ via SPSS software (SPSS 22.0, Nlinedown, Guangdong, China).

\subsection{Bioinformatics Analysis Content and Tools Website}

The primary structure was analyzed by using ProtParam. The website is http:/ / web. expasy.org/protparam/, accessed on 9 April 2019. The domain was analyzed by using SMART and InterProScan. The websites are http://smart.embl-heidelberg.de/, accessed on 9 April 2019 and ftp://ftp.ebi.ac.uk/pub/soft-ware/unix/iprscan/5/, accessed on 9 April 2019. 


\section{Conclusions}

Cucumber CsRSF1 and CsRSF2 genes acted as positive modulators in the response of cucumber to $S$. fuliginea infections, and their regulatory mechanisms might be different. They participated in the defense response to $S$. fuliginea by regulating the expression of certain defense-related genes. In summary, this research provided new insights into the important roles of CsRSF1 and CSRSF2 in the resistance to S. fuliginea. This research laid a good foundation for exploring the molecular mechanism of cucumber resistance to S. fuliginea and breeding resistant varieties.

Supplementary Materials: The following are available online at https: / www.mdpi.com/article/ 10.3390/ijms22083986/s1, Figure S1: Nucleotide and deduced amino acid sequences of cucumber CSRSF1 CDS encoding a protein. Figure S2: Nucleotide and deduced amino acid sequences of cucumber CSRSF2 CDS encoding a protein. Figure S3: Chromosome location of NBS-LRR superfamily in the cucumber. Figure S4: The structural domain of CsRSF protein. Table S1: The primers of PCR used in this study. Table S2: The primers of qRT-PCR used in this study.

Author Contributions: X.W. designed the research, analyzed the data and wrote the manuscript. J.H., Q.C., X.M. and N.C. conducted the experiments. H.F. and Y.Y. revised the paper. All authors have read and agreed to the published version of the manuscript.

Funding: This research was funded by the National Key Research and Development Program of China (2019YFD1000300) and Liaoning Provincial Natural Science Foundation Guidance Plan (20180550919).

Data Availability Statement: All data presented in article and supplementary materials.

Acknowledgments: The authors are grateful to the Liaoning Academy of Agricultural Sciences for providing seeds of the B21-a-2-2-2, B21-a-2-1-2 and Zhihong Zhang of Shenyang Agricultural University for providing the carriers.

Conflicts of Interest: The authors declare that this research was conducted in the absence of any financial or commercial relationships that could be interpreted as a potential conflict of interest.

\section{References}

1. Shen, H.; You, C.; Zhang, Y.; Cheng, F.; Guo, S.; Sun, J. Research Progress on Comprehensive Control of Cucumber Pow-Dery Mildew. Heilongjiang Agric. Sci. 2017, 8, 133-137. [CrossRef]

2. Yue, H.; Wu, X.; Hao, J.; Cui, J.; Zhang, S.; Zhang, X.; Bai, Z. Status and Prospects in Molecular Breeding of Powdery Mildew Resistance in Cucumber. J. Plant Genet. Resour. 2014, 15, 120-128. [CrossRef]

3. Lyon, G.; Newton, A.; Walters, D. Induced Resistance in Crop Protection: The Future, Drivers and Barriers. Induc. Resist. Plant Def. 2007, 243-249. [CrossRef]

4. Dangl, J.L.; Jones, J.D.G. Plant Pathogens and Integrated Defence Responses to Infection. Nat. Cell Biol. 2001, 411, 826-833. [CrossRef] [PubMed]

5. Ausubel, F.M. Are Innate Immune Signaling Pathways in Plants and Animals Conserved? Nat. Immunol. 2005, 6, 973-979. [CrossRef]

6. Hayashi, K.; Fujita, Y.; Ashizawa, T.; Suzuki, F.; Nagamura, Y.; Hayano-Saito, Y. Serotonin Attenuates Biotic Stress and Leads to Lesion Browning Caused by a Hypersensitive Response to Magnaporthe Oryzaepenetration in Rice. Plant J. 2016, 85, 46-56. [CrossRef]

7. Iwai, T.; Miyasaka, A.; Seo, S.; Ohashi, Y. Contribution of Ethylene Biosynthesis for Resistance to Blast Fungus Infection in Young Rice Plants. Plant Physiol. 2006, 142, 1202-1215. [CrossRef]

8. Eichmann, R.; Schäfer, P. The Endoplasmic Reticulum in Plant Immunity and Cell Death. Front. Plant Sci. 2012, 3, 200. [CrossRef]

9. Saha, D.; Rana, R.S.; Sureja, A.K.; Verma, M.; Arya, L.; Das Munshi, A. Cloning and Characterization of NBS-LRR Encoding Resistance Gene Candidates from Tomato Leaf Curl New Delhi Virus Resistant Genotype of Luffa Cylindrica Roem. Physiol. Mol. Plant Pathol. 2013, 81, 107-117. [CrossRef]

10. Van Ooijen, G.; Burg, H.A.V.D.; Cornelissen, B.J.C.; Takken, F.L.W. Structure and Function of Resistance Proteins in Solanaceous Plants. Annu. Rev. Phytopathol. 2007, 45, 43-72. [CrossRef]

11. Meyers, B.C.; Kozik, A.; Griego, A.; Kuang, H.; Michelmore, R.W. Genome-Wide Analysis of NBS-LRR-Encoding Genes in Arabidopsis. Plant Cell 2003, 15, 809-834. [CrossRef] [PubMed]

12. Xu, Y.; Liu, F.; Zhu, S.; Li, X. The Maize NBS-LRR Gene ZmNBS25 Enhances Disease Resistance in Rice and Arabidopsis. Front. Plant Sci. 2018, 9, 1033. [CrossRef] [PubMed] 
13. Belkin, M.E.; Sigov, A.S. Some Trend in Super-High Frequency Optoelectronics. J. Commun. Technol. Electron. 2009, 54, 855-868. [CrossRef]

14. Sharma, R.; Rawat, V.; Suresh, C. Genome-Wide Identification and Tissue-Specific Expression Analysis of Nucleotide Binding Site-Leucine Rich Repeat Gene Family in CICER Arietinum (Kabuli Chickpea). Genom. Data 2017, 14, 24-31. [CrossRef] [PubMed]

15. Zhou, Z.; Pang, Z.; Zhao, S.; Zhang, L.; Lv, Q.; Yin, D.; Li, D.; Liu, X.; Zhao, X.; Li, X.; et al. Importance of OsRac1 and RAI1 in Signalling of Nucleotide-Binding Site Leucine-Rich Repeat Protein-Mediated Resistance to Rice Blast Disease. New Phytol. 2019, 223, 828-838. [CrossRef]

16. Tameling, W.I.L.; Elzinga, S.D.J.; Darmin, P.S.; Vossen, J.H.; Takken, F.L.W.; Haring, M.A.; Cornelissen, B.J.C. The Tomato R Gene Products I-2 and Mi-1 Are Functional ATP Binding Proteins with ATPase Activity. Plant Cell 2002, 14, 2929-2939. [CrossRef]

17. Chen, M.; Wu, J.; Wang, L.; Mantri, N.; Zhang, X.; Zhu, Z.; Wang, S. Mapping and Genetic Structure Analysis of the Anthracnose Resistance Locus Co-1HY in the Common Bean (Phaseolus vulgaris L.). PLoS ONE 2017, 12, e0169954. [CrossRef]

18. Wu, J.; Zhu, J.; Wang, L.; Wang, S. Genome-Wide Association Study Identifies NBS-LRR-Encoding Genes Related with Anthracnose and Common Bacterial Blight in the Common Bean. Front. Plant Sci. 2017, 8, 1398. [CrossRef]

19. Zou, S.; Wang, H.; Li, Y.; Kong, Z.; Tang, D. The NB-LRR Gene Pm60 Confers Powdery Mildew Resistance in Wheat. New Phytol. 2017, 218, 298-309. [CrossRef]

20. Zhou, X.; Liu, J.; Bao, S.; Yang, Y.; Zhuang, Y. Molecular Cloning and Characterization of a Wild Eggplant Solanum Aculeatissimum NBS-LRR Gene, Involved in Plant Resistance to Meloidogyne incognita. Int. J. Mol. Sci. 2018, 19, 583. [CrossRef]

21. Jiang, N.; Cui, J.; Meng, J.; Luan, Y. A Tomato Nucleotide Binding Sites-Leucine-Rich Repeat Gene Is Positively Involved in Plant Resistance to Phytophthora infestans. Phytopathology 2018, 108, 980-987. [CrossRef]

22. Li, N.-Y.; Zhou, L.; Zhang, D.-D.; Klosterman, S.J.; Li, T.-G.; Gui, Y.-J.; Kong, Z.-Q.; Ma, X.-F.; Short, D.P.G.; Zhang, W.-Q.; et al. Heterologous Expression of the Cotton NBS-LRR Gene GbaNA1 Enhances Verticillium Wilt Resistance in Arabidopsis. Front. Plant Sci. 2018, 9, 119. [CrossRef] [PubMed]

23. Calil, I.P.; Fontes, E.P.B. Plant Immunity against Viruses: Antiviral Immune Receptors in Focus. Ann. Bot. 2016, 119, 711-723. [CrossRef] [PubMed]

24. Shen, Q.-H.; Saijo, Y.; Mauch, S.; Biskup, C.; Bieri, S.; Keller, B.; Seki, H.; Ülker, B.; Somssich, I.E.; Schulze-Lefert, P. Nuclear Activity of MLA Immune Receptors Links Isolate-Specific and Basal Disease-Resistance Responses. Science 2007, 315, 1098-1103. [CrossRef]

25. Chang, C.; Yu, D.; Jiao, J.; Jing, S.; Schulze-Lefert, P.; Shen, Q.-H. Barley MLA Immune Receptors Directly Interfere with Antagonistically Acting Transcription Factors to Initiate Disease Resistance Signaling. Plant Cell 2013, 25, 1158-1173. [CrossRef]

26. Inoue, H.; Hayashi, N.; Matsushita, A.; Xinqiong, L.; Nakayama, A.; Sugano, S.; Jiang, C.-J.; Takatsuji, H. Blast Resistance of CC-NB-LRR Protein Pb1 is Mediated by WRKY45 through Protein-Protein Interaction. Proc. Natl. Acad. Sci. USA 2013, 110, 9577-9582. [CrossRef]

27. Wirthmueller, L.; Zhang, Y.; Jones, J.D.; Parker, J.E. Nuclear Accumulation of the Arabidopsis Immune Receptor RPS4 Is Necessary for Triggering EDS1-Dependent Defense. Curr. Biol. 2007, 17, 2023-2029. [CrossRef] [PubMed]

28. García, A.V.; Blanvillain-Baufumé, S.; Huibers, R.P.; Wiermer, M.; Li, G.; Gobbato, E.; Rietz, S.; Parker, J.E. Balanced Nuclear and Cytoplasmic Activities of EDS1 Are Required for a Complete Plant Innate Immune Response. PLoS Pathog. 2010, 6, e1000970. [CrossRef]

29. Heidrich, K.; Wirthmueller, L.; Tasset, C.; Pouzet, C.; Deslandes, L.; Parker, J.E. Arabidopsis EDS1 Connects Pathogen Effector Recognition to Cell Compartment-Specific Immune Responses. Science 2011, 334, 1401-1404. [CrossRef] [PubMed]

30. Tameling, W.I.; Nooijen, C.; Ludwig, N.; Boter, M.; Slootweg, E.; Goverse, A.; Shirasu, K.; Joosten, M.H. RanGAP2 Mediates Nucleocytoplasmic Partitioning of the NB-LRR Immune Receptor Rx in the Solanaceae, Thereby Dictating Rx Function. Plant Cell 2010, 22, 4176-4194. [CrossRef]

31. Wan, H.; Yuan, W.; Bo, K.; Shen, J.; Pang, X.; Chen, J. Genome-Wide Analysis of NBS-Encoding Disease Resistance Genes in Cucumis Sativus and Phylogenetic Study of NBS-Encoding Genes in Cucurbitaceae Crops. BMC Genom. 2013, 14, 109. [CrossRef]

32. Xiao, S.; Ellwood, S.; Calis, O.; Patrick, E.; Li, T.; Coleman, M.; Turner, J.G. Broad-Spectrum Mildew Resistance in Arabidopsis thaliana Mediated by RPW8. Science 2001, 291, 118-120. [CrossRef]

33. Liu, Z.C. Inheritance Analysis and QTL Mapping of Powdery Mildew Resistance in Cucumber. Ph.D. Thesis, Shanghai Jiao-Tong University, Shanghai, China, 2008.

34. Luo, J.; Zhang, R.; Qi, X.; Xu, Q.; Chen, X. A Preliminary Study on Cloning of Chitinase Gene and Relationships to Resistance of Powdery Mildew in Cucumber (Cucumis sativus L.). Mol. Plant Breed. 2015, 13, 1584-1591.

35. Yu, G.C. Differential Proteome Analysis of Cucumber Resistant and Sensitive Sister Leaves in Response to S. fuliginea. Master's thesis, Shenyang Agricultural University, Shengyang, China, 2008.

36. Meng, X.; Song, T.; Fan, H.; Yu, Y.; Cui, N.; Zhao, J.; Meng, K. A Comparative Cell Wall Proteomic Analysis of Cucumber Leaves under Sphaerotheca Fuliginea Stress. Acta Physiol. Plant. 2016, 38, 260. [CrossRef]

37. Panstruga, R.; Kuhn, H. Mutual Interplay between Phytopathogenic Powdery Mildew Fungi and Other Microorganisms. Mol. Plant Pathol. 2018, 20, 463-470. [CrossRef] [PubMed]

38. Yang, L.; Li, D.; Li, Y.; Gu, X.; Huang, S.; Garcia-Mas, J.; Weng, Y. A 1,681-Locus Consensus Genetic Map of Cultivated Cucumber Including 67 NB-LRR Resistance Gene Homolog and Ten Gene Loci. BMC Plant Biol. 2013, 13, 53. [CrossRef] 
39. Zhang, S.P.; Liu, M.M.; Miao, H.; Zhang, S.Q.; Yang, Y.H.; Xie, B.Y. QTL Mapping of Resistance Genes to Powdery Mildew in Cucumber (Cucumis sativus L.). Sci. Agric. Sin. 2011, 44, 3584-3593.

40. Ameline-Torregrosa, C.; Wang, B.-B.; O’Bleness, M.S.; Deshpande, S.; Zhu, H.; Roe, B.; Young, N.D.; Cannon, S.B. Identification and Characterization of Nucleotide-Binding Site-Leucine-Rich Repeat Genes in the Model Plant Medicago truncatula. Plant Physiol. 2008, 146, 5-21. [CrossRef] [PubMed]

41. Gao, Y.; Xu, Z.; Jiao, F.; Yu, H.; Xiao, B.; Li, Y.; Lu, X. Cloning, Structural Features, and Expression Analysis of Resistance Gene Analogs in Tobacco. Mol. Biol. Rep. 2009, 37, 345-354. [CrossRef] [PubMed]

42. He, H.; Zhu, S.; Zhao, R.; Jiang, Z.; Ji, Y.; Ji, J.; Qiu, D.; Li, H.; Bie, T. Pm21, Encoding a Typical CC-NBS-LRR Protein, Confers Broad-Spectrum Resistance to Wheat Powdery Mildew Disease. Mol. Plant 2018, 11, 879-882. [CrossRef]

43. Dowen, R.H.; Engel, J.L.; Shao, F.; Ecker, J.R.; Dixon, J.E. A Family of Bacterial Cysteine Protease Type III Effectors Utilizes Acylation-Dependent and Independent Strategies to Localize to Plasma Membranes. J. Biol. Chem. 2009, 284, 15867-15879. [CrossRef] [PubMed]

44. Liu, J.; Elmore, J.M.; Lin, Z.-J.D.; Coaker, G. A Receptor-Like Cytoplasmic Kinase Phosphorylates the Host Target RIN4, Leading to the Activation of a Plant Innate Immune Receptor. Cell Host Microbe 2011, 9, 137-146. [CrossRef]

45. Cui, Y.; Jiang, J.; Yang, H.; Zhao, T.; Xu, X.; Li, J. Virus-Induced Gene Silencing (VIGS) of the NBS-LRR Gene SLNLC1 Compromises Sm-Mediated Disease Resistance to Stemphylium Lycopersici in Tomato. Biochem. Biophys. Res. Commun. 2018, 503, 1524-1529. [CrossRef]

46. Chakraborty, J.; Priya, P.; Dastidar, S.G.; Das, S. Physical Interaction between Nuclear Accumulated CC-NB-ARC-LRR Protein and WRKY64 Promotes EDS1 Dependent Fusarium Wilt Resistance in Chickpea. Plant Sci. 2018, 276, 111-133. [CrossRef] [PubMed]

47. Shang, Y.; Ma, Y.; Zhou, Y.; Zhang, H.; Duan, L.; Chen, H.; Zeng, J.; Zhou, Q.; Wang, S.; Gu, W.; et al. Biosynthesis, Regulation, and Domestication of Bitterness in Cucumber. Science 2014, 346, 1084-1088. [CrossRef] [PubMed]

48. Bari, R.; Jones, J.D.G. Role of Plant Hormones in Plant Defence Responses. Plant Mol. Biol. 2009, 69, 473-488. [CrossRef]

49. Divi, U.K.; Rahman, T.; Krishna, P. Brassinosteroid-Mediated Stress Tolerance in Arabidopsis Shows Interactions with Abscisic Acid, Ethylene and Salicylic Acid Pathways. BMC Plant Biol. 2010, 10, 151. [CrossRef]

50. Ton, J.; Flors, V.; Mauch-Mani, B. The Multifaceted Role of ABA in Disease Resistance. Trends Plant Sci. 2009, 14, 310-317. [CrossRef] [PubMed]

51. Roberts, M.; Tang, S.; Stallmann, A.; Dangl, J.L.; Bonardi, V. Genetic Requirements for Signaling from an Autoactive Plant NB-LRR Intracellular Innate Immune Receptor. PLoS Genet. 2013, 9, e1003465. [CrossRef]

52. Mohr, P.G.; Cahill, D.M. Relative Roles of Glyceollin, Lignin and the Hypersensitive Response and the Influence of ABA in Compatible and Incompatible Interactions of Soybeans with Phytophthora Sojae. Physiol. Mol. Plant Pathol. 2001, 58, 31-41. [CrossRef]

53. Adie, B.A.; Pérez-Pérez, J.; Pérez-Pérez, M.M.; Godoy, M.; Sánchez-Serrano, J.-J.; Schmelz, E.A.; Solano, R. ABA Is an Essential Signal for Plant Resistance to Pathogens Affecting JA Biosynthesis and the Activation of Defenses in Arabidopsis. Plant Cell 2007, 19, 1665-1681. [CrossRef] [PubMed]

54. De Vleesschauwer, D.; Van Buyten, E.; Satoh, K.; Balidion, J.; Mauleon, R.; Choi, I.-R.; Vera-Cruz, C.; Kikuchi, S.; Höfte, M. Brassinosteroids Antagonize Gibberellin- and Salicylate-Mediated Root Immunity in Rice. Plant Physiol. 2012, 158, $1833-1846$. [CrossRef] [PubMed]

55. De Torres-Zabala, M.; Truman, W.; Bennett, M.H.; Lafforgue, G.; Mansfield, J.W.; Egea, P.R.; Bögre, L.; Grant, M. Pseudomonas Syringae pv. Tomato Hijacks the Arabidopsis Abscisic Acid Signalling Pathway to Cause Disease. EMBO J. 2007, 26, 1434-1443. [CrossRef] [PubMed]

56. Browse, J. Jasmonate Passes Muster: A Receptor and Targets for the Defense Hormone. Annu. Rev. Plant Biol. 2009, 60, 183-205. [CrossRef] [PubMed]

57. Niu, J.; Liu, J.; Yin, J.; Ni, Y. Induction of PR-1, PR-2, PR-5, Ta-JA2 and Wheat Powdery Mildew Resistance in Response to MeJA Treatment. Acta Phytopathol. Sin. 2001, 41, 270-277. [CrossRef]

58. Epple, P.; Apel, K.; Bohlmann, H. An Arabidopsis Thaliana Thionin Gene Is Inducible via a Signal Transduction Pathway Different from That for Pathogenesis-Related Proteins. Plant Physiol. 1995, 109, 813-820. [CrossRef]

59. Penninckx, I.A.; Eggermont, K.; Terras, F.R.; Thomma, B.P.; De Samblanx, G.W.; Buchala, A.; Métraux, J.P.; Manners, J.M.; Broekaert, W.F. Pathogen-Induced Systemic Activation of a Plant Defensin Gene in Arabidopsis Follows a Salicylic AcidIndependent Pathway. Plant Cell 1996, 8, 2309-2323. [CrossRef]

60. Durner, J.; Shah, J.; Klessig, D.F. Salicylic Acid and Disease Resistance in Plants. Trends Plant Sci. 1997, 2, 266-274. [CrossRef]

61. Yang, Y.; Shah, J.; Klessig, D.F. Signal Perception and Transduction in Plant Defense Responses. Genes Dev. 1997, 11, 1621-1639. [CrossRef]

62. Broekaert, W.F.; Delauré, S.L.; De Bolle, M.F.C.; Cammue, B.P.A. The Role of Ethylene in Host-Pathogen Interactions. Annu. Rev. Phytopathol. 2006, 44, 393-416. [CrossRef]

63. Van Loon, L.C.; Rep, M.; Pieterse, C.M.J. Significance of Inducible Defense-Related Proteins in Infected Plants. Annu. Rev. Phytopathol. 2006, 44, 135-162. [CrossRef]

64. Beckers, G.J.M.; Spoel, S.H. Fine-Tuning Plant Defence Signalling: Salicylate versus Jasmonate. Plant Biol. 2006, 8, 1-10. [CrossRef] 
65. Mur, L.A.; Kenton, P.; Atzorn, R.; Miersch, O.; Wasternack, C. The Outcomes of Concentration-Specific Interactions between Salicylate and Jasmonate Signaling Include Synergy, Antagonism, and Oxidative Stress Leading to Cell Death. Plant Physiol. 2006, 140, 249-262. [CrossRef]

66. Nahar, K.; Kyndt, T.; Nzogela, Y.B.; Gheysen, G. Abscisic acid Interacts Antagonistically with Classical Defense Pathways in Rice-Migratory Nematode Interaction. New Phytol. 2012, 196, 901-913. [CrossRef]

67. Vos, I.A.; Emoritz, L.; Pieterse, C.M.J.; Van Wees, S.C.M. Impact of Hormonal Crosstalk on Plant Resistance and Fitness under Multi-Attacker Conditions. Front. Plant Sci. 2015, 6, 639. [CrossRef] [PubMed]

68. Takahashi, H.; Miller, J.; Nozaki, Y.; Takeda, M.; Shah, J.; Hase, S.; Ikegami, M.; Ehara, V.; Dinesh-KumaR, S.P.; Sukamto, R. CY1, an Arabidopsis Thaliana RPP8/HRT Family Resistance Gene, Conferring Resistance to Cucumber Mosaic Virus Requires Salicylic Acid, Ethylene and a Novel Signal Transduction Mechanism. Plant J. 2002, 32, 655-667. [CrossRef]

69. Navarro, L.; Bari, R.; Achard, P.; Lisón, P.; Nemri, A.; Harberd, N.P.; Jones, J.D. DELLAs Control Plant Immune Responses by Modulating the Balance of Jasmonic Acid and Salicylic Acid Signaling. Curr. Biol. 2008, 18, 650-655. [CrossRef] [PubMed]

70. Zhu, X.; Lu, C.; Du, L.; Ye, X.; Liu, X.; Coules, A.; Zhang, Z. The Wheat NB-LRR Gene TaRCR1 is Required for Host Defence Response to the Necrotrophic Fungal Pathogen Rhizoctonia Cerealis. Plant Biotechnol. J. 2017, 15, 674-687. [CrossRef] [PubMed]

71. Kumar, V.; Parkhi, V.; Kenerley, C.M.; Rathore, K.S. Defense-Related Gene Expression and Enzyme Activities in Transgenic Cotton Plants Expressing an Endochitinase Gene from Trichoderma Virens in Response to Interaction with Rhizoctonia Solani. Planta 2009, 230, 277-291. [CrossRef]

72. Wang, Q.; Li, Y.; Ishikawa, K.; Kosami, K.-I.; Uno, K.; Nagawa, S.; Tan, L.; Du, J.; Shimamoto, K.; Kawano, Y. Resistance Protein Pit Interacts with the GEF OsSPK1 to Activate OsRac1 and Trigger Rice Immunity. Proc. Natl. Acad. Sci. USA 2018, 115, E11551-E11560. [CrossRef]

73. Li, T.; Wang, B.; Yin, C.; Zhang, D.; Wang, D.; Song, J.; Zhou, L.; Kong, Z.; Klosterman, S.J.; Li, J.; et al. The Gossypium Hirsutum TIR-NBS-LRR Gene GhDSC1 Mediates Resistance against Verticillium Wilt. Mol. Plant Pathol. 2019, 20, 857-876. [CrossRef]

74. Ren, H.M. Study on the Inhibitory Mechanism of Chrysophanol on S. fuliginea. Ph.D. Thesis, Hebei Agricultural University, Baoding, China, 2011.

75. Wang, D.D. Studies on Mechanism, More of Action of Dpintol against Sphaerotheca Fulijinea and Its Mixture with Other Pestcides. Master's Thesis, Shanghai Jiaotong University, Shanghai, China, 2013. 